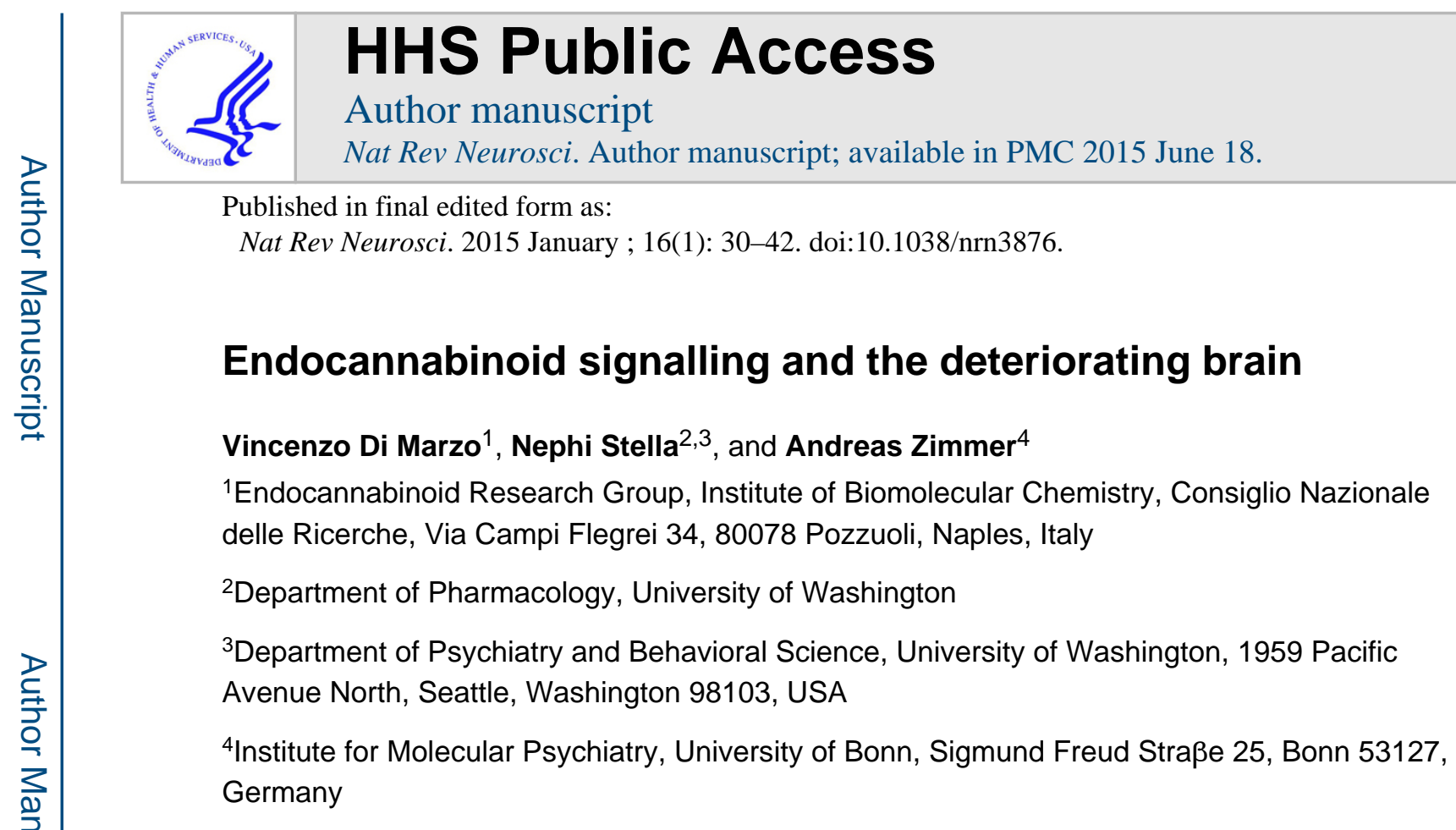

\title{
Abstract
}

Ageing is characterized by the progressive impairment of physiological functions and increased risk of developing debilitating disorders, including chronic inflammation and neurodegenerative diseases. These disorders have common molecular mechanisms that can be targeted therapeutically. In the wake of the approval of the first cannabinoid-based drug for the symptomatic treatment of multiple sclerosis, we examine how endocannabinoid $(\mathrm{eCB})$ signalling controls - and is affected by - normal ageing and neuroinflammatory and neurodegenerative disorders. We propose a conceptual framework linking eCB signalling to the control of the cellular and molecular hallmarks of these processes, and categorize the key components of endocannabinoid signalling that may serve as targets for novel therapeutics.

\begin{abstract}
After millennia of anecdotal use (both medicinal and recreational) of Cannabis plants, as described in Chinese, Indian and Arab pharmacopeias ${ }^{1}$, centuries of their documented medicinal use throughout the world, and nearly five decades of research on the mechanism of action of their bioactive constituents (the phytocannabinoids), the medical use of cannabis extracts was approved in June 2010 by ten European countries ${ }^{2}$. This first Cannabis-based medicine (known as nabiximols in the United States and marketed as Sativex (GW Pharmaceuticals) in more than 25 countries worldwide) was prepared by combining botanical extracts from two varieties of Cannabis sativa plants, one producing mainly $\Delta^{9}$ tetrahydrocannabinol (THC; the major psychotropic component in the flowers) and the other
\end{abstract}

\footnotetext{
(C) 2014 Macmillan Publishers Limited. All rights reserved

Correspondence to V.D., vdimarzo@icb.cnr.it.

Competing interests statement

The authors declare competing interests: see Web version for details.

FURTHER INFORMATION

Vincenzo Di Marzo's homepage: http://www.icb.cnr.it/erg

Andreas Zimmer's homepage: http://www.molpsychiatrie.uni-bonn.de/

SUPPLEMENTARY INFORMATION

See online article: S1 (table)
} 
producing mainly cannabidiol (CBD; an abundant non-psychotropic phytocannabinoid), with a ratio of approximately 1:1. Thus, despite the medicinal uses of THC for the treatment of emesis and cachexia in patients with cancer undergoing chemotherapy, and for promoting appetite in patients with $\operatorname{AIDS}^{1,3}$, cannabis extracts were finally given bona fide therapeutic status after a decade of clinical trials dedicated to the testing of a combination of THC and $\mathrm{CBD}$ on the neurodegenerative disease multiple sclerosis.

A wealth of results obtained from animal models and human studies over the past two decades greatly increased our understanding of the molecular mechanism by which THC, its endogenous 'counterparts' (the endocannabinoids, eCBs) and its synthetic analogues, modulate cannabinoids receptors. These studies also provided scientific support for targeting the $\mathrm{eCB}$ signalling system to treat several devastating diseases, including neurodegenerative and chronic inflammatory diseases. This Review focuses on recent evidence that has added a new layer of complexity to the idea of targeting the eCB signalling system for therapeutic benefit, as it is now clear that the expression level of the different molecular components forming this signalling system (the receptors and enzymes producing and inactivating eCBs) change substantially both in the brain and peripheral tissues as a function of ageing. This suggests that the bioactivity of eCB-based therapeutics is likely to vary depending on the age of the patient, the disease type and the stage of disease at the time of treatment ${ }^{4,5}$. Accordingly, such treatments may have to be tailored for different subsets of patients.

\section{The endocannabinoid system}

The first guanine-nucleotide-binding protein (G protein)-coupled receptor (GPCR) activated by THC, cannabinoid receptor 1 (CB1; encoded by gene $C N R 1$ ), was discovered in the brain in 1988 (REF. 6) and cloned in 1990, (REF. 7) and the second GPCR, CB2, was identified in immune cells in 1993 (REF. 8). More than 70 phytocannabinoids are present in Cannabis plants (in varying amounts depending on strain or growing conditions), but only THC potently activates CB1 and CB2. The existence of these two receptors, of which one (CB1) is the most abundant GPCR in the brain, could only be explained by the presence of endogenous ligands; the eCBs. These were discovered in the early nineties, shortly after the discoveries of $\mathrm{CB} 1$ and $\mathrm{CB} 2$, as derivatives of the non-oxidative metabolism of the polyunsaturated fatty acid, arachidonic acid. $N$-arachidonoyl-ethanolamine (anandamide) ${ }^{9}$ and 2-arachidonoyl-glycerol (2-AG) ${ }^{10,11}$ are the two best-studied eCBs so far, and together with enzymes involved in their biosynthesis and inactivation ${ }^{12}$, and the two cannabinoid receptors, they form the 'eCB system'. $\mathrm{CB} 1$ receptors are most abundant in brain regions such as the hippocampus, cortex, basal ganglia and cerebellum, and expressed in both excitatory (glutamatergic) and inhibitory (GABAergic) presynaptic terminals, although their postsynaptic localization has also been observed ${ }^{13,14}$. In the healthy brain, CB2 receptors are barely detectable, although they seem to be present in some neuronal populations ${ }^{13}$. However, CB2 receptor expression can increase in both microglia and astrocytes under specific conditions of neuroinflammation (see below) ${ }^{13}$. Both CB1 and CB2 receptors couple to $G$ protein type $G_{i / o}$, and less frequently to the $G_{q / 11}$ type. It is through this coupling that they activate mitogen-activated protein kinases (MAPK) such as extracellular signal-regulated kinase 1 (ERK1), ERK2, p38 MAPKs and JUN N-terminal kinases (JNKs), and inhibit adenylate cyclase and cyclic AMP-protein kinase A (PKA) signalling. 
Activation of $\mathrm{CB} 1$ receptors also inhibits $\mathrm{L}-, \mathrm{N}$ - and P/Q-type voltage-activated $\mathrm{Ca}^{2+}$ channels and stimulates inwardly rectifying $\mathrm{K}^{+}$channels, the result of which is to reduce neurotransmitter release ${ }^{15}$.

Anandamide is a high-affinity, low-efficacy CB1 agonist, with even lower efficacy at CB2 receptors, whereas 2-AG has lower affinity, but is a fully effective agonist at both $\mathrm{CB} 1$ and CB2 (REF. 16). The eCBs are produced from phospholipid precursors when intracellular $\mathrm{Ca}^{2+}$ is elevated, following either neuron depolarization or activation of metabotropic $\mathrm{G}_{\mathrm{q} / 11^{-}}$ coupled receptors. Anandamide, like other $N$-acylethanolamines (NAEs), is produced from the hydrolysis of the corresponding $N$-acylphosphatidylethanolamine (NAPE) ${ }^{17}$. This can occur in one step, when catalysed by the NAPE-selective phospholipase D (NAPE-PLD) enzyme $^{18}$, or in two or three steps through alternative routes ${ }^{19,20}$. 2-AG and other 2acylglycerols are produced in one step from the hydrolysis of diacylglycerols (DAGs) by either of two diacylglycerol lipases (DAGLs), DAGLa or DAGL $\beta$ (REF. 21), although in the adult brain it is the former of these two enzymes that accounts for nearly all of 2-AG acting as an $\mathrm{eCB}^{22}$. DAGs are produced in most cases from the hydrolysis of phosphoinositides by phospholipase $\mathrm{C} \beta$ (PLC $\beta)^{23}$. Although most eCB biosynthetic enzymes are sensitive to $\mathrm{Ca}^{2+}$, it is thought that the rate controlling and $\mathrm{Ca}^{2+}$-dependent steps in anandamide and 2-AG formation are undertaken by NAPE and DAG biosynthesis, respectively. $\mathrm{A} \mathrm{Ca}^{2+}$-dependent acyltransferase ${ }^{24}$ catalyses the biosynthesis of NAPEs through the transfer of the corresponding acyl chains from the $s n-1$ position of phospholipids to the amine group of phosphatidylethanolamine; however, its molecular identity has not yet been reported.

eCBs are taken up by cells through a mechanism that is not yet elucidated fully — but likely to involve membrane carriers, intracellular carrier proteins and/or possibly endocytosis ${ }^{25}-$ and are then inactivated by enzymatic hydrolysis. For anandamide, this reaction is catalysed uniquely by fatty acid amide hydrolase 1 (FAAH) ${ }^{26}$, whereas for 2-AG most of this reaction seems to be catalysed by monoacylglycerol lipase (MAGL) ${ }^{27}$, although ABHD6 (an abbreviation of $\alpha, \beta$ hydrolase 6$)^{28}$ and ABHD12, as well as FAAH ${ }^{29}$, are also capable of hydrolysing this $\mathrm{eCB}$. Both anandamide and 2-AG are also oxidized by the enzyme cyclooxygenase 2 (COX2; also known as prostaglandin $\mathrm{G} / \mathrm{H}$ synthase 2$)^{30}$.

The postsynaptic and presynaptic distribution in the brain of DAGLa and MAGL, respectively, is ideal for enabling the retrograde inhibition of potentially excessive neurotransmitter release by $2-\mathrm{AG}$ activation of presynaptic CB1 receptors ${ }^{31}$ (FIG. 1). Indeed, a flurry of landmark studies have demonstrated the pleiotropic nature of the eCB system, which is activated locally and on demand to regulate specific physiological functions, often following perturbations of homeostasis, to help restore a physiological steady state in mammalian cells, organs and organisms ${ }^{32}$.

How eCB signalling controls specific cellular functions, and how various cannabinoid agonists and antagonists modulate these functions is now much better understood, owing to the power of new pharmacological tools and genetic models capable of interrogating individual components of this system in selected cell populations. These approaches demonstrated that $\mathrm{CB} 1$ receptor signalling differs between glutamatergic and GABAergic 
neurons (see below), and also established that anandamide can activate non-cannabinoid receptors - the transient receptor potential cation channel subfamily V member 1 (TRPV1) channel and, possibly, the peroxisome proliferator-activated receptor- $\gamma(\operatorname{PPAR} \gamma)^{33,34}$ which confer further functional flexibility to this mediator. Together, the wealth of studies using these powerful tools has provided a picture of the role and components of eCB signalling in the healthy brain. Here we review how the basic components of this signalling system are affected by, and in turn regulate, ageing-related processes, and outline the molecular commonalities between the deregulation of this signalling system in normal ageing and during neuroinflammation and neurodegeneration.

\section{Endocannabinoid signalling in ageing}

There are numerous lines of evidence from rodents and humans to indicate that $\mathrm{eCB}$ signalling undergoes age-dependent changes. In rodents, the CB1 mRNA levels and/or specific binding of CB1 agonists in the brain peak at the onset of puberty, stay at a relatively stable high level in the adult ${ }^{35}$, and decline markedly in the cerebellum, cortex, and hippocampal and hypothalamic structures of older animals ${ }^{36}$. The old-age-dependent decrease in receptor availability to the plasma membrane is likely to be due to posttranscriptional mechanisms, because changes in CB1 mRNA levels do not always reflect changes in the density of receptor binding and hence the amount of CB1 protein $^{36,37}$. Furthermore, the coupling of $\mathrm{CB} 1$ receptors to $\mathrm{G}$ proteins is also reduced in specific brain areas in older animals ${ }^{38}$. The levels of NAPE-PLD mRNA and protein increase during early post-natal development of rats ${ }^{39}$. This is accompanied by increasing brain anandamide concentrations during the early postnatal period ${ }^{40}$, with a peak at the onset of puberty ${ }^{41}$. Studies in humans also showed that CB1 receptor levels are much higher in younger compared to older individuals ${ }^{42,43}$. The levels of CB1 mRNA decrease by approximately $50 \%$ (REF. 44), and binding of the non-selective cannabinoid receptor agonist $\left[{ }^{3} \mathrm{H}\right]$ CP55,940 also decreases in cortical tissues of older individuals ${ }^{45}$. The mRNA levels of eCB biosynthetic and metabolic enzymes also change during ageing in the human prefrontal cortex. NAPE-PLD levels increase continuously during ageing, whereas DAGLa peaks in young adulthood and declines in older individuals. FAAH mRNA shows only a minor increase with ageing. MAGL mRNA levels are highest during infancy and decrease thereafter, while ABHD6 levels increase steadily throughout life ${ }^{44}$. Notably, we still do not know whether these changes correlate with corresponding changes in the levels of eCBs. Nevertheless, these data indicate that the age-related changes in the expression of the components of eCB signalling are similar in rodents and humans. These changes might be responsible for some of the age-specific alterations in behavioural paradigms measured both under basal conditions and following cannabinoid exposure. This could explain why, at a young age ( 2 months), animals lacking CB1 show better performance than wild-type littermate controls in several learning and memory tasks. Remarkably, when older individuals are tested, the outcome is the opposite. Specifically, at age 3-5 months, CB1null mice no longer perform better, and in fact sometimes perform worse, than wild-type controls. When they are 12 months old, CB1-null mice perform substantially worse than wild-type animals in all cognitive tests used in these studies ${ }^{46-48}$. Exposure of animals to doses of THC in the range that cause psychoactive effects has been shown to impair 
cognitive functions ${ }^{49}$, similar to observations in humans after cannabis exposure ${ }^{50}$. These cognitive deficits persist even after an extended period of abstinence ${ }^{51}$, and it has been suggested that cannabis use during early life may accelerate brain pathologies associated with ageing and psychiatric disorders ${ }^{52,53}$. However, it is important to note that almost all studies on these THC effects, even in rodents, were performed with younger or adult (but not aged) individuals ${ }^{54,55}$ and it remains unclear how relevant these results are to older individuals.

Evidence obtained with new-generation genetic mouse models in which selective components of eCB signalling were knocked out globally or in specific cell populations indicate that disrupting this system affects fundamental aspects of the normal ageing process. For example, the age-dependent acceleration of cognitive decline in mice with global deletion of CB1 is accompanied by accelerated loss of hippocampal CA1 and CA3 neurons, and induction of reactive astrogliosis in this brain region, as well as an increased number of activated microglia and enhanced levels of pro-inflammatory cytokines ${ }^{56}$. This phenotype is similar to that observed in mice with a deletion of CB1 selectively in GABAergic neurons; however, CB1 deletion in glutamatergic neurons does not induce any marked age-related cognitive deficits ${ }^{47,56}$. These data indicate that absence of CB1 receptors in specific neuronal types accelerates the appearance of brain ageing indicators, including neuronal loss and chronic neuroinflammation. Importantly, this phenotype is only observed in the brain and the skin of these animals, and not in other organs, suggesting a tissuespecific aspect of the involvement of eCB signalling in ageing ${ }^{56}$. The expression profile and role of $\mathrm{CB} 2$ receptors in mouse brain remains to be established clearly, but it is interesting to note that mice lacking CB2 receptors show a phenotype that is also reminiscent of accelerated ageing, although outside of the brain. These mice suffer from severe osteoporosis ${ }^{57,58}$, which is consistent with the reported function of this receptor in bone biology. Overall, these studies indicate that the disruption of cannabinoid receptors seems to enhance age-related decline in a number of tissues in which they have important physiological functions, and implicate eCB signalling in the control of the ageing process ${ }^{59}$ (FIG. 2).

One of the hallmarks of ageing in rodents that is known to be influenced by eCB signalling is the depletion and eventual exhaustion of neural stem cell populations. Proliferation of progenitor cells in the rodent hippocampus and olfactory bulb is reduced by at least $50 \%$ in older animals (aged over 14 months) compared to younger individuals (aged 2-6 months) ${ }^{60}$. This particular response to ageing probably involves both cell-extrinsic factors and alterations in the network of genes regulating proliferation, in particular those controlling eCB signalling ${ }^{61,62}$. Indeed, pharmacological compounds that enhance CB1 and CB2 activity, including inhibitors of anandamide degradation by FAAH, stimulate adult hippocampal neurogenesis ${ }^{63-66}$, whereas inhibition of eCB biosynthesis reduces it ${ }^{67,68}$. These pharmacological findings are supported by genetic studies showing that the deletion of CB1 receptors or the 2-AG-producing enzyme DAGLa reduce the proliferation of neuronal progenitors to approximately $50 \%$ of that of wild-type controls ${ }^{67,69}$. Conversely, mice with deletion of FAAH, which exhibit higher levels of anandamide in brain, show increased levels of adult neurogenesis ${ }^{70}$. As these experiments were performed in 4-monthold adult mice, it will be important to establish whether impaired eCB stimulation of 
neurogenesis underlies at least part of the neuronal decline typical of ageing. Furthermore, CB1 receptors also have a crucial role in axonal guidance, distance migration of neurons and synapse formation during brain development ${ }^{71}$, whereas activation of both cannabinoid receptors is needed to stimulate myelin formation in the subcortical white matter ${ }^{72}$. Notably, eCB signalling is also likely to have a crucial role in insult-induced adult neuron replacement and remyelination. How this fundamental function of $\mathrm{eCBs}$ on progenitor cells is affected by ageing is not known.

\section{Endocannabinoids and neuroinflammation}

The expression level of both cannabinoid and eCB-related receptors in neurons and glial cells may change independently either as a function of normal ageing or earlier in life in response to a neurological disease ${ }^{73}$ (FIG. 2). In neurological disease, chronic alterations in eCB signalling are often accompanied with chronic activation of the immune system and a number of immune cells that invade the brain parenchyma also express such receptors and thus contribute to the number of cells that will respond to eCB and cannabinoids ${ }^{74}$. This dynamic change in brain neuroinflammation in $\mathrm{eCB}$ signalling in neurons, glia and immune cells has been mapped in detail in mice undergoing experimental allergic encephalomyelitis (EAE), a model of multiple sclerosis. For example, resting microglial cells in the healthy adult brain express low levels of CB2, whereas induction of EAE induces a 200-fold upregulation in the expression of this receptor in activated microglia ${ }^{75}$. As CB2 receptors regulate the cellular function of microglia and macrophages (both important mediators of EAE pathogenesis) ${ }^{76}$, such a pronounced upregulation of these receptors in these cells might at first suggest that $\mathrm{eCB}$ signalling represents a critical molecular component controlling neuroinflammation and pathogenesis in EAE mouse models. However, an elegant study performed with a conditional genetic mouse model that enabled control of CB2 receptor expression in invading immune $\mathrm{T}$ cells in adult mice showed that it is this smaller population of cannabinoid receptors expressed by invading immune cells that has a key role in the development of the pathogenesis modeled by $\mathrm{EAE}^{77}$. These findings provide an example of how low levels of cannabinoid receptors expressed by non-CNS cells may critically control disease initiation and progression (FIG. 3). It is unknown whether the ability to control neuroinflammation (and allied neurodegeneration through the action of cannabinoids on invading T cells) changes as a function of ageing. Furthermore, how ageing might predispose individuals affected by multiple sclerosis or other neuroinflammatory disorders to cannabinoid-based treatments also remains an open question.

Variations in the levels of eCBs are also important to survey, as any change in the expression of cannabinoid receptors will alter their functionality, particularly if accompanied by a corresponding change in its endogenous agonists. Such changes in eCB levels have been detected in plasma from patients with multiple sclerosis ${ }^{78}$, as well as in patients with disorders ranging from Parkinson's disease and Huntington's disease to amyotrophic lateral sclerosis, and/or in tissues from the corresponding animal models ${ }^{79}$. These changes are likely to be influenced also by age-related alterations in the composition of the $\mathrm{eCB}$ signalling system. Therefore, to understand the possible role of this system in neuroinflammatory conditions, the field still needs to outline how cannabinoid receptor expression in neurons, astrocytes, microglia and invading immune cells, as well as eCB 
bioavailability, are affected by ageing. A better understanding of these processes will be essential if cannabinoid-based treatments are to be optimized for patients of different ages suffering from distinct disorders.

A key hallmark of ageing is found in the age-dependent deregulation of intercellular communication. This deregulation affects neuronal, endocrine and immune cell signalling ${ }^{80}$, and the molecular components involved in this process are potential targets for the prevention of age-related disorders. One example of deregulated intercellular communication that has been studied extensively occurs in monocytes and macrophages major cellular components of the innate immune system - as ageing is often accompanied by accumulation of a low-grade pro-inflammatory milieu in certain tissues. This phenomenon has been termed 'inflammaging' ${ }^{21}$. Specifically, older individuals have elevated levels of pro-inflammatory cytokines and nuclear factor- $\kappa \mathrm{B}(\mathrm{NF}-\kappa \mathrm{B})$ signalling, and consequently, increased expression of inflammation-related proteins that are regulated by these molecules. This process is not unidirectional, as inflammaging also engages counter-adaptive processes, which include the activation of the hypothalamic-pituitaryadrenal (HPA) axis, resulting in an increased release of anti-inflammatory cortisol. Thus, it is thought that the balance between these opposing processes is an important determinant of the health-related consequences of ageing. Although the function of eCBs in inflammaging has not been studied in detail, decades of research indicate that this signalling system is an important modulator of immune cell functions and inflammatory responses. For example, it is known that brain eCB signalling is activated by stress ${ }^{82}$ as well as by pro-inflammatory stimuli, and is involved in the maintenance of HPA and immune homeostasis ${ }^{83}$. As mentioned above, mice with CB1 deletion show all characteristics of an increased inflammaging condition in the brain, indicating that CB1 activation is important to counteract this process. These findings suggest that during ageing and neuroinflammation (or when both are present together) there is a disruption of brain tissue homeostasis that involves eCB signalling, and that this contributes to specific cell dysfunction. Furthermore, downregulation of $\mathrm{CB} 1$ receptors induced by chronic THC administration, or deletion of CB1, also cause cerebellar microglial activation in mice ${ }^{84}$.

Another hallmark of ageing that is worth exploring is how age-related pathology that occurs in one tissue can adversely affect other tissues. Indeed, it was shown recently that a proinflammatory response that develops in the hypothalamus of older mice can exacerbate ageing-related changes in the physiology outside the brain, including changes in muscle endurance, dermal thickness, bone mass, tendon elasticity and cognitive performance in the whole animal $^{85}$. In line with this evidence, inhibiting the age-related induction of hypothalamic inhibitor of nuclear factor- $\kappa \mathrm{B}$ kinase subunit- $\beta$ (IKK- $\beta$ ) or NF- $\kappa \mathrm{B}$ (which have both been shown to be crucial to hypothalamic inflammation in older mice) reduces the agerelated cognitive decline of these animals and prolongs their lifespan ${ }^{85}$. Interestingly, eCB signalling in the hypothalamus controls the HPA axis ${ }^{82}$ and modulates energy homeostasis in peripheral tissues. Activation of hypothalamic CB1 receptors induces orexigenic effects and inhibits energy expenditure. However, production of eCBs in the hypothalamus is inhibited by leptin ${ }^{86}$, a hormone produced peripherally that has anorexigenic effects (increases energy expenditure and suppresses appetite) but also has pro-inflammatory actions ${ }^{87}$. In adult mice with obesity induced by a high-fat diet, eCB signalling in the 
hypothalamus becomes deregulated following the development of leptin resistance in the arcuate nucleus, but not in other hypothalamic and extra-hypothalamic areas (see REF. 88 and references cited therein). This response is one likely cause of increased food intake and reduced energy expenditure, and contributes to further accumulation of adipose tissue and more leptin release. In turn, leptin promotes pro-inflammatory responses that might contribute to inducing gliosis and hence promote ageing and neuroinflammatory disorders, particularly multiple sclerosis ${ }^{87,89}$. Thus, although the activation of eCB signalling in lean animals may counteract neuroinflammation (but less so in older animals), the opposite may be true during obesity (and possibly more so in older animals), indicating an overarching change in the functionality of $\mathrm{eCB}$ signalling associated with ageing and disease with different, and sometimes even opposing, effects.

\section{eCB signalling, cell metabolism and disease}

Many of the signalling events downstream of cannabinoid receptors are known to funnel through molecular integrators ('hub' molecules) within the intracellular signalling networks that control basic cell functions, including cell viability and, by extension, normal ageing. One key downstream signalling event of CB1 (and leptin) receptors is the serine/threonine kinase mammalian target of rapamycin (mTOR), a molecular integrator that enables both cellular nutrient sensing and energy homeostasis (FIG. 2) through the ERK/MAPK-Akt pathway (FIG. 1). Specifically, mTOR is located in two multiprotein complexes, mTORC1 and mTORC2, which control anabolic metabolism through regulation of protein translation ${ }^{90}$. The mTORC1 complex has a role in regulating synaptic plasticity and cognitive functions, including memory, through mechanisms that depend on de novo protein synthesis. Acute injections of THC induce rapid and transient stimulation of mTORC1 activity in the hippocampus, striatum, cerebellum, frontal cortex and amygdala ${ }^{91,92}$, whereas repeated administration of THC leads to more sustained activation of mTORC1, lasting for several days after the cessation of treatment ${ }^{92}$. Accordingly, the amnesic effects of THC depends on mTOR signalling and can be abolished by the mTOR inhibitor rapamycin. Further supporting a functional link between these modalities, deregulated mTOR activity is associated with metabolic, neurological and psychiatric disorders, and overactivation of mTOR signalling through enhanced eCB activity contributes to cognitive impairment in fragile $\mathrm{X}$ syndrome ${ }^{93}$. Deregulation of this system is likely to represent an important sign of ageing 59 .

The regulation of mTORC1 by CB1 receptors is remarkably wide-ranging, as mTOR has also been implicated as a central regulator of autophagy, a cellular response thought to contribute to the ageing-associated loss of protein homeostasis or 'proteostasis'. Proteostasis refers to cellular processes of stabilizing correctly folded functional proteins, or removing misfolded dysfunctional ones through proteasomal or lysosomal mechanisms.

Fundamentally, autophagy (or specifically, macroautophagy) is a cytoprotective mechanism through which potentially harmful cytoplasmatic components are sequestered in vesicles and delivered to lysosomes for degradation ${ }^{94}$. This process can also provide nutrients under conditions of starvation. Evidence shows that autophagy is reduced in aged tissues and that rapamycin, and hence mTOR inhibition, increases lifespan mainly through induction of autophagy ${ }^{95}$. Interestingly, autophagy measured in cancer cells is also induced by eCB 
signalling ${ }^{96-98}$. However, the underlying mechanism of this latter response is unlikely to involve the above-mentioned CB1 activation of mTOR, as this mechanism inhibits (rather than stimulates) autophagy. Indeed, there is also evidence for inhibition of autophagy by eCB signalling, as CB1 antagonism and global deletion of CB1 were found to enhance autophagy flux in mice, although in an mTOR-independent manner ${ }^{99}$. Mice with CB1 deletion show a significantly increased accumulation of lipofuscin ${ }^{100}$, an age-related lipopigment that consists of highly crosslinked non-degradable lysosomal aggregates harmful to cells ${ }^{101}$. This phenomenon was related to a decreased expression of the lysosomal enzyme cathepsin $\mathrm{D}$, which indicates that lysosomal degradation is impaired. Thus, in mice with CB1 deletion, the enhanced autophagy may be secondary to a reduced expression of cathepsin D, rather than inhibition of $\mathrm{mTOR}^{100}$ (FIG. 2).

The depiction of the molecular mechanisms mediating the age-dependent deregulation of eCB signalling and regulation of autophagy reveals an overlapping signalling framework that encompasses several common molecular hubs, many of which have also been implicated in Huntington's disease. This devastating autosomal-dominant neurodegenerative disease is caused by CAG expansions in exon 1 of the IT15 gene (also known as HTT), which encodes the protein huntingtin ${ }^{102}$. Mutated huntingtin directly affects the expression of many genes and the activity of many enzymes that participate together in the development of this disease ${ }^{102,103}$. A remarkably early response induced by mutant huntingtin is to inhibit the Cnrl promoter in neurons. This early downregulation of CB1 receptor expression can be detected in the neurons of human patients with Huntington's disease, and genetic mouse and cellular models of Huntington's disease ${ }^{49,104}$. Recently, genetic manipulations (deletion or rescue) of CB1 receptor expression in select neuronal populations of Huntington's disease genetic mouse models demonstrated that downregulation of this receptor has a key role in striatal neurodegeneration, including the loss of cortical-striatal connections ${ }^{105,106}$. Thus, an additional conceptual link may be drawn that connects the age-dependent loss of functional CB1 receptors in select neuronal populations, which influence mTOR1 signalling, to the ability to promote autophagy in this neuronal population, with the two contributing together to the loss of functional synaptic contacts associated with Huntington's disease.

An additional parallel may be found in studies showing that eCBs prevents amyloid- $\beta$ induced lysosomal destabilization in cortical neurons. Importantly, this activity is dependent on lysosomal CB1 receptors, but not on receptors located on the cell surface ${ }^{107}$. Indeed, it has been suggested recently that eCB signalling may be involved not only in intercellular but in intracellular communication through its ability to regulate the functions of intracellular organelles. In some cells, a substantial proportion of CB1 receptors are localized on lysosomes ${ }^{108-110}$, where they may be functionally active ${ }^{109}$. Furthermore, CB1 receptors have been found recently on the external membrane of brain mitochondria ${ }^{111}$. Although this finding is still somewhat controversial ${ }^{112}$, these mitochondrial receptors seem to regulate neuronal energy metabolism directly, because incubation of isolated mitochondria with THC reduces the activity of the respiratory chain complex I, decreases the level of mitochondrial cAMP, and decreases mitochondrial PKA activity ${ }^{112}$ (FIG. 1). The putative mitochondrial CB1 receptors were also shown to contribute to a form of eCB- 
mediated short-term feedback inhibition of synaptic activity, termed depolarization-induced suppression of inhibition, with potential impact on cognitive function ${ }^{111}$. These findings are important in light of the fact that mitochondrial dysfunctions contribute to physiological ageing ${ }^{59}$ as well as neurodegenerative disorders ${ }^{113}$.

In summary, the studies reviewed so far, together with evidence suggesting that changes in eCB levels might have a role in amyotrophic lateral sclerosis and Parkinson's disease ${ }^{79}$, outline a molecular framework that connects extra- and intracellular eCB signalling to an age- and cell-metabolism-dependent deterioration of neural cells that might contribute to some neurodegenerative diseases.

\section{The endocannabinoidome in neurodegeneration}

Since the discovery of anandamide and 2-AG, it has been clear that these signalling lipids are accompanied in tissues by congeners; that is, other NAEs and 2-acylglycerols. These lipids are biologically active and share with the two eCBs their respective biosynthetic and inactivating enzymes (FIG. 1), but not their ability to activate CB1 and CB2 receptors. We now know that the brain concentrations of NAE and 2-acylglycerol congeners increase in animals treated with inhibitors of eCB-hydrolysing enzymes (FAAH or MAGL), as well as in mice lacking these enzymes ${ }^{114,115}$. Remarkably, most congeners activate more than one receptor (Supplementary information S1 (table)) and many of these eCB-related receptors are expressed by different cell types of the CNS and have been shown to be involved in ageing and neuroinflammation and/or neurodegeneration. Thus, for example, when the activity of FAAH is blocked in animal models of Parkinson's or Huntington's disease ${ }^{116,117}$, non-CB1-, non-CB2-mediated biological responses might be produced by NAE congeners, and this needs to be taken into consideration when interpreting the role of this enzyme in such pathological states.

NAEs and 2-acylglycerols are not the only examples of eCB-related mediators produced by cells. Amides of several fatty acids with amino acids (known as lipoaminoacids) or amine transmitters (such as the $N$-acyldopamines and $N$-acylserotonins) ${ }^{118-120}$, have been isolated and their bioactivity investigated. Although our current knowledge of the biochemistry of these putative lipid mediators is still limited, it has been observed that their biosynthesis or degradation might be affected when FAAH is inhibited ${ }^{118,120}$. The role of these long-chain fatty acid derivatives in the ageing brain or during neurodegenerative disorders is largely understudied, yet several molecular targets involved in excitotoxicity and neuroinflammation are known to be modulated by them (Supplementary information S1 (table)). Striking examples are T-type $\mathrm{Ca}^{2+}$ channels (particularly $\mathrm{Ca}_{\mathrm{v}} 3.2$ and $\mathrm{Ca}_{\mathrm{v}} 3.3$ ), which are involved in the establishment of associative long-term potentiation, and whose levels wane with ageing ${ }^{121}$. These channels are blocked by physiological concentrations of $\mathrm{N}$-arachidonoyldopamine and $\mathrm{N}$-arachidonoylserotonin, which exhibit nanomolar affinity in binding assays and are therefore among their strongest endogenous inhibitors ${ }^{122}$. Thus, if the levels of these eCB-like mediators were to be enhanced or reduced following pharmacological inhibition of FAAH, this could impact upon synaptic plasticity and potentially result in memory disturbances. These memory deficits could be more problematic if the levels of these mediators were shown to be altered during ageing. 
To complicate things further, both anandamide and 2-AG can be oxidized efficiently by enzymes of the arachidonate cascade, in particular by $\mathrm{COX} 2$, and thus yield yet another class of bioactive lipids that act through yet other sets of receptors ${ }^{30,123}$. This reaction has now been demonstrated to occur also in vivo, especially under conditions in which COX2 is upregulated, and eventually leads to prostaglandin ethanolamides (or prostamides) and prostaglandin glycerol esters for anandamide and 2-AG, respectively. These metabolites produce biological effects via GPCRs that are pharmacologically different from both cannabinoid and prostaglandin receptors and are yet to be fully identified at the molecular level ${ }^{124}$. It is reasonable to expect that the formation of these bioactive metabolites is enhanced following pharmacological inhibition of the hydrolytic catabolism of eCBs by FAAH and MAGL (or ABHD6) ${ }^{123}$. One example was reported in relation to the neurotoxicity model of striatal neurons induced by malonate (which, if injected into the striatum of rats, produces effects that recapitulate some of the features of Huntington's disease). In this model, inhibitors of MAGL (which would increase 2-AG accumulation and thus would be expected to be neuroprotective) were found, surprisingly, to worsen malonate-induced neurotoxicity and neuroinflammation, whereas inhibition of 2-AG biosynthesis by blocking DAGLa produced beneficial effects ${ }^{125}$. The mechanism underlying these unexpected results appears to involve a bioactive COX2 metabolite of 2AG because treatment of striatal neurons with malonate in the presence MAGL inhibitors leads to the formation of prostaglandin E2 glycerol ester, which produces neurotoxic effects attenuated by a specific antagonist of prostaglandin E2 glycerol ester receptors ${ }^{125}$. Another example comes from experimental models of Parkinson's disease, in which 2-AG, which has been known for decades to act as a biosynthetic precursor for arachidonic acid and eicosanoids in sensory neurons, may contribute to the neuroinflammatory response. Genetic or pharmacological inhibition of MAGL leads to reduced activity in the prostaglandinmediated pro-inflammatory signalling cascades that underlie the neurodegeneration process measured in this model ${ }^{126}$. A key control was to show that the amelioration of Parkinson's disease pathogenesis following MAGL inhibition was not due to indirect activation of cannabinoid receptors, but instead to reduction of prostaglandin biosynthesis via the 2-AGarachidonate pathway ${ }^{126}$. Additional evidence comes from animal models of Alzheimer's disease. In one study ${ }^{127}$, inhibition of MAGL was shown to attenuate neuroinflammation and lower amyloid- $\beta$ levels and plaques, effects that seem to involve 2-AG-derived prostaglandins. In another study, inhibiting MAGL prevented neuroinflammation, neurodegeneration and decreases in integrity of hippocampal synaptic structure and function, thereby improving long-term synaptic plasticity, spatial learning and memory ${ }^{128}$. In both these studies, the effects were independent of CB1 and CB2 receptors. Thus, MAGL inhibitors might cause opposing actions on neuroinflammation depending on whether or not, in a given context and experimental set-up, 2-AG acts as a substrate for COX2 per se, thereby producing pro-inflammatory prostaglandin E2 glycerol ester, or only after its hydrolysis to arachidonic acid, thereby producing more conventional pro-inflammatory prostaglandins (FIG. 4).

The multifunctionality of these bioactive lipids is still more complex than discussed above. At submicromolar concentrations, anandamide and 2-AG - even before their catabolism may modulate the activity of additional non-cannabinoid receptors directly. Modulating 
these other targets may either reduce or enhance the potential therapeutic advantage of agents designed to pharmacologically manipulate eCB tissue levels. For example, activation of TRPV1 channels is perhaps the best-established non-CB1-, non-CB2-receptor-mediated action of anandamide ${ }^{33}$. TRPV1 is expressed by both central neurons and glial cells (although less abundantly than in peripheral sensory neurons), and is involved in exacerbating glutamate excitotoxicity and neuroinflammation ${ }^{129}$; yet activation of this channel also contributes to changes in synaptic plasticity that can be beneficial to behavioural and cognitive deficits associated with neurodegenerative disorders ${ }^{129,130}$. Accordingly, TRPV1 activation can both exacerbate and counteract some of the major symptoms in animal models of Parkinson's and Huntington's diseases ${ }^{116,117,131,132}$. Another example is found in 2-AG that directly enhances $\mathrm{GABA}_{\mathrm{A}}$ receptor activity ${ }^{133}$, which may influence several aspects of ageing and neurodegeneration, including excitotoxicity, the development of neuroinflammation and the establishment of synaptic plasticity. Finally, both anandamide and 2-AG may also activate PPAR $\gamma$, which is also emerging as a player in the control of neuronal activity and neuroinflammation by these signalling lipids ${ }^{34,134}$.

When reviewing this evidence, it is possible to see that the discovery of the eCB system has in fact unravelled a new world of lipid mediators, enzymes and molecular targets, which could be seen as an 'endocannabinoidome' (Supplementary information S1 (table)). This concept is not just a matter of mere definitions, or of viewing things in a holistic manner, but may influence the future planning, design and eventual testing — in appropriate patient populations - of drugs that interfere with selected molecular components of this complex signalling system.

\section{Concluding remarks}

The wealth of studies on the action of eCBs and synthetic cannabinoids at CB1 and CB2 receptors in the context of neuroinflammation, neurodegeneration and ageing points to several molecular hubs that are likely to dictate the cellular response induced by these ligands. For example, as eCBs modulate a wide range of biological function through specific receptors, the enzymes involved in their inactivation provide a target through which one can indirectly regulate the activity of such receptors and, hence, the pathological consequences of their malfunctioning. A control mechanism over eCB levels and signalling has been reported for FAAH, MGL and ABHD6, and we now understand that these enzymatic hubs control the levels of several distinct signalling lipids that target a broad panel of receptors within a signalling framework. A recent example of this complexity was provided with ABHD6 inhibitors that control seizure incidence in a mouse model of the juvenile form of Huntington's disease, an effect mediated by the action of $2-\mathrm{AG}$ at $\mathrm{GABA}_{\mathrm{A}}$ rather than cannabinoid receptors ${ }^{135}$. We also appreciate that this fine tuning of receptor activity by signalling lipids is in sharp contrast to the more sustained bioavailability of synthetic agonists, which is mainly determined by their pharmacokinetic profile typified by their accumulation in brain tissue. Thus, it will be important to bear in mind that control of cellular responses by synthetic compounds will not precisely mimic the more rapid and time- and space-specific activation and inactivation by endogenous signalling lipids. In particular, when considering the role of the eCB signalling system in controlling multiple 
modalities involved in ageing, neuroinflammation and neurodegeneration, a framework appears in which either one or several components of the endocannabinoidome may have to be targeted for therapy (TABLE 1). Specifically, the effects of manipulating eCB levels pharmacologically using inhibitors of FAAH and MAGL have been tested in experimental models of multiple sclerosis, and Alzheimer's, Parkinson's and Huntington's diseases, often yielding contradictory results, possibly owing to the intrinsic differences and heterogeneity of these model systems. Such inhibitors produce clear symptomatic relief (in terms of alleviation of spasticity) in chronic or relapsing $\mathrm{EAE}^{136}$, and this might be one way by which CBD contributes to the anti-spasticity effects of Sativex in multiple sclerosis, as this phytocannabinoid is known to inhibit FAAH and can lead to increases in AEA levels in humans ${ }^{137,138}$. Importantly, following induction of EAE, reduced neuroinflammation and neurodegeneration have also been shown in mice with FAAH deletion compared to wildtype mice ${ }^{139,140}$. By contrast, studies testing the efficacy of FAAH inhibitors in animal models of Alzheimer's, Parkinson's and Huntington's diseases and of amyotrophic lateral sclerosis have been less successful. Possible explanations include: the potential harmful role played by eCB signalling in the Alzheimer's- and Parkinson's-disease-like pathogenesis (to the point that CB1 blockers also produce beneficial actions in these cases) ${ }^{141,142}$; the possibility of inducing indirect activation of non-cannabinoid receptors (for example, TRPV1 channels) when inhibiting FAAH in Parkinson's and Huntington's diseases ${ }^{116,117}$; the downregulated CB1 receptor expression and/or FAAH activity in Huntington's disease ${ }^{117,143,144}$; the seemingly opposite roles of CB1 and CB2 receptors in determining survival in the superoxide dismutase (SOD1) mouse model of amyotrophic lateral sclerosis $^{145}$; and the different role of CB1 receptors when expressed on glutamatergic versus GABAergic terminals (neuroprotective only in the former case), for example, in a model of Huntington's disease ${ }^{106}$. Indeed, differential coupling and function between CB1 receptors expressed by either glutamatergic and GABAergic neurons has been described in detail ${ }^{146}$. Thus, it is also possible that, owing to the time- and age-dependent nature of neurodegenerative disorders, and the plastic changes and roles of cannabinoid and eCBrelated receptors in each of their phases (FIGS 3,4), similar therapeutic effects might be observed with drugs producing opposite actions on eCB actions or levels ${ }^{117,125}$; or an inhibitor of eCB inactivation might produce both amelioration and worsening of the symptoms, in different phases of a given condition ${ }^{147}$. These considerations provide a strong stepping stone to develop new therapies for both symptom alleviation and disease modification in neuroinflammatory and neurodegenerative disorders based on the pharmacological manipulation of eCB signalling, which may be a challenging but nevertheless fascinating task for our field of research to tackle in the future.

\section{Supplementary Material}

Refer to Web version on PubMed Central for supplementary material.

\section{Acknowledgments}

Research in the laboratory of A.Z. was funded by the Deutsche Forschungsgemeinschaft (FOR926, SFB645) and is a member of Excellence Cluster Immunosensation. N.S. is funded by the US National Institutes of Health (NIH; DA014486 and DA026430). V.D. acknowledges Progetto Operativo Nazionale (PON01_02512) and FIRB-MERIT grant number RBNE08HWLZ_006, for funding, and is a recipient of unrestricted grants from GW Pharmaceuticals, 
UK, and Allergan, USA. The authors wish to thank L. De Petrocellis and E. Drews for their help during the preparation of this manuscript.

\section{References}

1. Mechoulam, R., editor. Cannabis as Therapeutic Agent. CRC Press; Roca Ranton: 1986. p. 1-19.

2. Kmietowicz Z. Cannabis based drug is licensed for spasticity in patients with MS. BMJ. 2010; 340:c3363. [PubMed: 20570870]

3. Pertwee RG. Cannabinoid pharmacology: the first 66 years. Br J Pharmacol. 2006; 147:S153-S171.

4. Bilkei-Gorzo A. The endocannabinoid system in normal and pathological brain ageing. Phil Trans $\mathrm{R}$ Soc B. 2012; 367:3326-3341. [PubMed: 23108550]

5. Velayudhan L, et al. Therapeutic potential of cannabinoids in neurodegenerative disorders: a selective review. Curr Pharm Des. 2014; 20:2218-2230. [PubMed: 23829360]

6. Devane WA, Dysarz FA, Johnson MR, Melvin LS, Howlett AC. Determination and characterization of a cannabinoid receptor in rat brain. Mol Pharmacol. 1988; 34:605-613. [PubMed: 2848184]

7. Matsuda LA, Lolait SJ, Brownstein MJ, Young AC, Bonner TI. Structure of a cannabinoid receptor and functional expression of the cloned cDNA. Nature. 1990; 346:561-564. [PubMed: 2165569]

8. Munro S, Thomas KL, Abu-Shaar M. Molecular characterization of a peripheral receptor for cannabinoids. Nature. 1993; 365:61-65. [PubMed: 7689702]

9. Devane WA, et al. Isolation and structure of a brain constituent that binds to the cannabinoid receptor. Science. 1992; 258:1946-1949. [PubMed: 1470919]

10. Mechoulam R, et al. Identification of an endogenous 2-monoglyceride, present in canine gut, that binds to cannabinoid receptors. Biochem Pharmacol. 1995; 50:83-90. [PubMed: 7605349]

11. Sugiura T, et al. 2-Arachidonoylglycerol: a possible endogenous cannabinoid receptor ligand in brain. Biochem Biophys Commun. 1995; 215:89-97.

12. Di Marzo V. Targeting the endocannabinoid system: to enhance or reduce? Nature Rev Drug Discov. 2008; 7:438-455. [PubMed: 18446159]

13. Onaivi ES, Ishiguro H, Gu S, Liu QR. CNS effects of CB2 cannabinoid receptors: beyond neuroimmuno-cannabinoid activity. J Psychopharmacol. 2012; 26:92-103. [PubMed: 21447538]

14. Mackie K. Distribution of cannabinoid receptors in the central and peripheral nervous system. Handb Exp Pharmacol. 2005; 168:299-325. [PubMed: 16596779]

15. Dalton GD, Bass CE, Van Horn CG, Howlett AC. Signal transduction via cannabinoid receptors. CNS Neurol Disord Drug Targets. 2009; 8:422-431. [PubMed: 19839935]

16. Gonsiorek W, et al. Endocannabinoid 2-arachidonyl glycerol is a full agonist through human type 2 cannabinoid receptor: antagonism by anandamide. Mol Pharmacol. 2000; 57:1045-1050. [PubMed: 10779390]

17. Di Marzo V, et al. Formation and inactivation of endogenous cannabinoid anandamide in central neurons. Nature. 1994; 372:686-691. [PubMed: 7990962]

18. Okamoto Y, Morishita J, Tsuboi K, Tonai T, Ueda N. Molecular characterization of a phospholipase D generating anandamide and its congeners. J Biol Chem. 2004; 279:5298-5305. [PubMed: 14634025]

19. Simon GM, Cravatt BF. Anandamide biosynthesis catalyzed by the phosphodiesterase GDE1 and detection of glycerophospho- $N$-acyl ethanolamine precursors in mouse brain. J Biol Chem. 2008; 283:9341-9349. [PubMed: 18227059]

20. Liu J, et al. Multiple pathways involved in the biosynthesis of anandamide. Neuropharmacology. 2008; 54:1-7. [PubMed: 17631919]

21. Bisogno $\mathrm{T}$, et al. Cloning of the first sn1-DAG lipases points to the spatial and temporal regulation of endocannabinoid signaling in the brain. J Cell Biol. 2003; 163:463-468. [PubMed: 14610053]

22. Tanimura A, et al. The endocannabinoid 2-arachidonoylglycerol produced by diacylglycerol lipase a mediates retrograde suppression of synaptic transmission. Neuron. 2010; 65:320-327. [PubMed: 20159446]

23. Lehmann DM, Yuan C, Smrcka AV. Analysis and pharmacological targeting of phospholipase C $\beta$ interactions with G proteins. Methods Enzymol. 2007; 434:29-48. [PubMed: 17954241] 
24. Cadas H, di Tomaso E, Piomelli D. Occurrence and biosynthesis of endogenous cannabinoid precursor, $N$-arachidonoyl phosphatidylethanolamine, in rat brain. J Neurosci. 1997; 17:12261242. [PubMed: 9006968]

25. Fowler CJ. Transport of endocannabinoids across the plasma membrane and within the cell. FEBS J. 2013; 280:1895-1904. [PubMed: 23441874]

26. Cravatt BF, et al. Molecular characterization of an enzyme that degrades neuromodulatory fattyacid amides. Nature. 1996; 384:83-87. [PubMed: 8900284]

27. Dinh TP, et al. Brain monoglyceride lipase participating in endocannabinoid inactivation. Proc Natl Acad Sci USA. 2002; 99:10819-10824. [PubMed: 12136125]

28. Marrs WR, et al. The serine hydrolase ABHD6 controls the accumulation and efficacy of 2-AG at cannabinoid receptors. Nature Neurosci. 2010; 13:951-957. [PubMed: 20657592]

29. Blankman JL, Simon GM, Cravatt BF. A comprehensive profile of brain enzymes that hydrolyze the endocannabinoid 2-arachidonoylglycerol. Chem Biol. 2007; 14:1347-1356. [PubMed: 18096503]

30. Kozak KR, et al. Metabolism of the endocannabinoids, 2-arachidonylglycerol and anandamide, into prostaglandin, thromboxane, and prostacyclin glycerol esters and ethanolamides. J Biol Chem. 2002; 277:44877-44885. [PubMed: 12244105]

31. Ohno-Shosaku T, Kano M. Endocannabinoid-mediated retrograde modulation of synaptic transmission. Curr Opin Neurobiol. 2014; 29:1-8. [PubMed: 24747340]

32. Di Marzo V, Bifulco M, De Petrocellis L. The endocannabinoid system and its therapeutic exploitation. Nature Rev Drug Discov. 2004; 3:771-784. [PubMed: 15340387]

33. Zygmunt PM, et al. Vanilloid receptors on sensory nerves mediate the vasodilator action of anandamide. Nature. 1999; 400:452-457. [PubMed: 10440374]

34. Bouaboula M, et al. Anandamide induced PPAR $\gamma$ transcriptional activation and 3T3-L1 preadipocyte differentiation. Eur J Pharmacol. 2005; 517:174-181. [PubMed: 15987634]

35. Rodriguez de Fonseca F, Ramos JA, Bonnin A, Fernández-Ruiz JJ. Presence of cannabinoid binding sites in the brain from early postnatal ages. Neuroreport. 1993; 4:135-138. [PubMed: 8453049]

36. Berrendero F, et al. Changes in cannabinoid receptor binding and mRNA levels in several brain regions of aged rats. Biochim Biophys Acta. 1998; 1407:205-214. [PubMed: 9748581]

37. McLaughlin CR, Martin BR, Compton DR, Abood ME. Cannabinoid receptors in developing rats: detection of mRNA and receptor binding. Drug Alcohol Depend. 1994; 36:27-31. [PubMed: 7988356]

38. Wang L, Liu J, Harvey-White J, Zimmer A, Kunos G. Endocannabinoid signaling via cannabinoid receptor 1 is involved in ethanol preference and its age-dependent decline in mice. Proc Natl Acad Sci USA. 2003; 100:1393-1398. [PubMed: 12538878]

39. Morishita J, et al. Regional distribution and age-dependent expression of $\mathrm{N}$ acylphosphatidylethanolamine-hydrolyzing phospholipase D in rat brain. J Neurochem. 2005; 94:753-762. [PubMed: 15992380]

40. Berrendero F, Sepe N, Ramos JA, Di Marzo V, Fernández-Ruiz JJ. Analysis of cannabinoid receptor binding and mRNA expression and endogenous cannabinoid contents in the developing rat brain during late gestation and early postnatal period. Synapse. 1999; 33:181-191. [PubMed: 10420166]

41. Wenger T, et al. The hypothalamic levels of the endocannabinoid, anandamide, peak immediately before the onset of puberty in female rats. Life Sci. 2002; 70:1407-1414. [PubMed: 11883716]

42. Glass M, Dragunow M, Faull RL. Cannabinoid receptors in the human brain: a detailed anatomical and quantitative autoradiographic study in the fetal, neonatal and adult human brain.

Neuroscience. 1997; 77:299-318. The first study showing impaired endocannabinoid signalling in Huntington's disease. [PubMed: 9472392]

43. Choi K, et al. Expression pattern of the cannabinoid receptor genes in the frontal cortex of mood disorder patients and mice selectively bred for high and low fear. J Psych Res. 2012; 46:882-889.

44. Long LE, Lind J, Webster M, Weickert CS. Developmental trajectory of the endocannabinoid system in human dorsolateral prefrontal cortex. BMC Neurosci. 2012; 13:87. [PubMed: 22827915] 
45. Westlake TM, Howlett AC, Bonner TI, Matsuda LA, Herkenham M. Cannabinoid receptor binding and messenger RNA expression in human brain: an in vitro receptor autoradiography and in situ hybridization histochemistry study of normal aged and Alzheimer's brains. Neuroscience. 1994; 63:637-652. [PubMed: 7898667]

46. Bilkei-Gorzo A, et al. Early age-related cognitive impairment in mice lacking cannabinoid CB1 receptors. Proc Natl Acad Sci USA. 2005; 102:15670-15675. This paper shows that brain ageing is accelerated in mice lacking cannabinoid CB1 receptors. [PubMed: 16221768]

47. Albayram O, et al. Role of CB1 cannabinoid receptors on GABAergic neurons in brain aging. Proc Natl Acad Sci USA. 2011; 108:11256-11261. [PubMed: 21690345]

48. Albayram O, Bilkei-Gorzó A, Zimmer A. Loss of CB1 receptors leads to differential age-related changes in reward-driven learning and memory. Front Aging Neurosci. 2012; 4:34. [PubMed: 23227007]

49. Han J, et al. Acute cannabinoids impair working memory through astroglial CB1 receptor modulation of hippocampal LTD. Cell. 2012; 148:1039-1050. [PubMed: 22385967]

50. Solowij N, et al. Verbal learning and memory in adolescent cannabis users, alcohol users and nonusers. Psychopharmacology. 2011; 216:131-144. [PubMed: 21328041]

51. Bolla KI, Brown K, Eldreth D, Tate K, Cadet JL. Dose-related neurocognitive effects of marijuana use. Neurology. 2002; 59:1337-1343. [PubMed: 12427880]

52. Mata I, et al. Gyrification brain abnormalities associated with adolescence and early-adulthood cannabis use. Brain Res. 2010; 1317:297-304. [PubMed: 20045399]

53. Solowij N, et al. Cerebellar white-matter changes in cannabis users with and without schizophrenia. Psychol Med. 2011; 41:2349-2359. [PubMed: 21466751]

54. Lundqvist T. Cognitive consequences of cannabis use: comparison with abuse of stimulants and heroin with regard to attention, memory and executive functions. Pharmacol Biochem Behav. 2005; 81:319-330. [PubMed: 15925403]

55. Solowij N, Battisti R. The chronic effects of cannabis on memory in humans: a review. Curr Drug Abuse Rev. 2008; 1:81-98. [PubMed: 19630708]

56. Bilkei-Gorzó A, et al. Early onset of aging-like changes is restricted to cognitive abilities and skin structure in $\mathrm{Cnr}^{-/-}$mice. Neurobiol Aging. 2012; 33:200.e11-22. [PubMed: 20724033]

57. Ofek O, et al. Peripheral cannabinoid receptor, CB2, regulates bone mass. Proc Natl Acad Sci USA. 2006; 103:696-701. This paper demonstrates that mice lacking cannabinoid CB2 receptors have an age-related osteoporosis phenotype. [PubMed: 16407142]

58. Bab I, Zimmer A. Cannabinoid receptors and the regulation of bone mass. Br J Pharmacol. 2008; 153:182-188. [PubMed: 18071301]

59. López-Otín C, Blasco MA, Partridge L, Serrano M, Kroemer G. The hallmarks of aging. Cell. 2013; 153:1194-1217. This review provides a comprehensive overview of prominent physiological changes that are associated with the ageing process. [PubMed: 23746838]

60. Hamilton LK, Joppé SE, Cochard M, Fernandes KJL. Aging and neurogenesis in the adult forebrain: what we have learned and where we should go from here. Eur J Neurosci. 2013; 37:1978-1986. [PubMed: 23773067]

61. Molofsky AV, et al. Increasing p16INK4a expression decreases forebrain progenitors and neurogenesis during ageing. Nature. 2006; 443:448-452. [PubMed: 16957738]

62. Jin K, et al. Neurogenesis and aging: FGF-2 and HB-EGF restore neurogenesis in hippocampus and subventricular zone of aged mice. Aging Cell. 2003; 2:175-183. [PubMed: 12882410]

63. Jiang W, et al. Cannabinoids promote embryonic and adult hippocampus neurogenesis and produce anxiolytic- and antidepressant-like effects. J Clin Invest. 2005; 115:3104-3116. [PubMed: 16224541]

64. Palazuelos J, et al. Non-psychoactive CB2 cannabinoid agonists stimulate neural progenitor proliferation. FASEB J. 2006; 20:2405-2407. [PubMed: 17015409]

65. Goncalves MB, et al. A diacylglycerol lipase-CB2 cannabinoid pathway regulates adult subventricular zone neurogenesis in an age-dependent manner. Mol Cell Neurosci. 2008; 38:526536. [PubMed: 18562209] 
66. Díaz-Alonso J, Guzmán M, Galve-Roperh I. Endocannabinoids via CB1 receptors act as neurogenic niche cues during cortical development. Phil Trans R Soc B. 2012; 367:3229-3241. [PubMed: 23108542]

67. Gao Y, et al. Loss of retrograde endocannabinoid signaling and reduced adult neurogenesis in diacylglycerol lipase knock-out mice. J Neurosci. 2010; 30:2017-2024. [PubMed: 20147530]

68. Oudin MJ, Hobbs C, Doherty P. DAGL-dependent endocannabinoid signalling: roles in axonal pathfinding, synaptic plasticity and adult neurogenesis. Eur J Neurosci. 2011; 34:1634-1646. [PubMed: 22103420]

69. Jin K, et al. Defective adult neurogenesis in CB1 cannabinoid receptor knockout mice. Mol Pharmacol. 2004; 66:204-208. [PubMed: 15266010]

70. Aguado T, et al. The endocannabinoid system drives neural progenitor proliferation. FASEB J. 2005; 19:1704-1706. [PubMed: 16037095]

71. Tortoriello G, et al. Miswiring the brain: $\Delta 9$-tetrahydrocannabinol disrupts cortical development by inducing an SCG10/stathmin-2 degradation pathway. EMBO J. 2014; 33:668-685. An important study showing for the first time the molecular mechanisms through which overactivation of CB1 may disrupt cortical development. [PubMed: 24469251]

72. Arévalo-Martín A, et al. Cannabinoids modulate Olig2 and polysialylated neural cell adhesion molecule expression in the subventricular zone of post-natal rats through cannabinoid receptor 1 and cannabinoid receptor 2. Eur J Neurosci. 2007; 26:1548-1559. [PubMed: 17880390]

73. Stella N. Cannabinoid and cannabinoid-like receptors in microglia, astrocytes, and astrocytomas. Glia. 2010; 58:1017-1030. [PubMed: 20468046]

74. Hegde VL, Nagarkatti M, Nagarkatti PS. Cannabinoid receptor activation leads to massive mobilization of myeloid-derived suppressor cells with potent immunosuppressive properties. Eur J Immunol. 2010; 40:3358-3371. [PubMed: 21110319]

75. Maresz K, Carrier EJ, Ponomarev ED, Hillard CJ, Dittel BN. Modulation of the cannabinoid CB receptor in microglial cells in response to inflammatory stimuli. J Neurochem. 2005; 95:437-445. [PubMed: 16086683]

76. Stella N. Endocannabinoid signaling in microglial cells. Neuropharmacology. 2009; 56:244-253. [PubMed: 18722389]

77. Maresz K, et al. Direct suppression of CNS autoimmune inflammation via the cannabinoid receptor CB1 on neurons and CB2 on autoreactive T cells. Nature Med. 2007; 13:492-497. [PubMed: 17401376]

78. Jean-Gilles L, et al. Plasma endocannabinoid levels in multiple sclerosis. J Neurol Sci. 2009; 287:212-215. [PubMed: 19695579]

79. Centonze D, Finazzi-Agro A, Bernardi G, Maccarrone M. The endocannabinoid system in targeting inflammatory neurodegenerative diseases. Trends Pharmacol Sci. 2007; 28:180-187. [PubMed: 17350694]

80. Russell SJ, Kahn CR. Endocrine regulation of ageing. Nature Rev Mol Cell Biol. 2007; 8:681-691. [PubMed: 17684529]

81. Franceschi C, et al. Inflamm-aging. An evolutionary perspective on immunosenescence. Ann NY Acad Sci. 2000; 908:244-254. [PubMed: 10911963]

82. Patel S, et al. Endocannabinoid signaling negatively modulates stress-induced activation of the hypothalamic-pituitary-adrenal axis. Endocrinology. 2004; 145:5431-5438. [PubMed: 15331569]

83. Zoppi S, et al. Regulatory role of cannabinoid receptor 1 in stress-induced excitotoxicity and neuroinflammation. Neuropsychopharmacology. 2011; 36:805-818. [PubMed: 21150911]

84. Cutando L, et al. Microglial activation underlies cerebellar deficits produced by repeated cannabis exposure. J Clin Invest. 2013; 123:2816-2831. This paper identifies microglial cell activation as the non-cell-autonomous mechanism mediating cerebellar deficits induced by semi-chronic exposure to THC, emphasizing the remarkable specificity in cell damage occurring under such regimen. [PubMed: 23934130]

85. Zhang G, et al. Hypothalamic programming of systemic ageing involving IKK- $\beta, N F-\kappa B$ and GnRH. Nature. 2013; 497:211-216. [PubMed: 23636330]

86. Di Marzo V, et al. Leptin-regulated endocannabinoids are involved in maintaining food intake. Nature. 2001; 410:822-825. [PubMed: 11298451] 
87. Conde J, et al. At the crossroad between immunity and metabolism: focus on leptin. Expert Rev Clin Immunol. 2010; 6:801-808. [PubMed: 20828288]

88. Cristino L, et al. Obesity-driven synaptic remodeling affects endocannabinoid control of orexinergic neurons. Proc Natl Acad Sci USA. 2013; 110:E2229-E2238. The first paper describing endocannabinoid-mediated mechanisms through which the orexinergic control of basic functions can be disrupted in obesity. [PubMed: 23630288]

89. Matarese G, et al. Leptin as a metabolic link to multiple sclerosis. Nature Rev Neurol. 2010; 6:455-461. [PubMed: 20606678]

90. Martínez de Morentin PB, et al. Hypothalamic mTOR: the rookie energy sensor. Curr Mol Med. 2014; 14:3-21. [PubMed: 24236459]

91. Puighermanal E, et al. Cannabinoid modulation of hippocampal long-term memory is mediated by mTOR signaling. Nature Neurosci. 2009; 12:1152-1158. [PubMed: 19648913]

92. Puighermanal E, et al. Dissociation of the Pharmacological Effects of THC by mTOR Blockade. Neuropsychopharmacology. 2013; 38:1334-1343. [PubMed: 23358238]

93. Busquets-Garcia A, et al. Targeting the endocannabinoid system in the treatment of fragile $\mathrm{X}$ syndrome. Nature Med. 2013; 19:603-607. The first study indicating how blockade of CB1 receptors might be useful in some rare forms of autism. [PubMed: 23542787]

94. Rubinsztein DC, Mariño G, Kroemer G. Autophagy and aging. Cell. 2011; 146:682-695. [PubMed: 21884931]

95. Kapahi P, et al. With TOR, less is more: a key role for the conserved nutrient-sensing TOR pathway in aging. Cell Metab. 2010; 11:453-465. [PubMed: 20519118]

96. Salazar M, et al. Cannabinoid action induces autophagy-mediated cell death through stimulation of ER stress in human glioma cells. J Clin Invest. 2009; 119:1359-1372. [PubMed: 19425170]

97. Salazar M, et al. TRB3 links ER stress to autophagy in cannabinoid anti-tumoral action. Autophagy. 2009; 57:1048-1049. [PubMed: 19652543]

98. Koay LC, Rigby RJ, Wright KL. Cannabinoid-induced autophagy regulates suppressor of cytokine signaling-3 in intestinal epithelium. Am J Physiol Gastrointest Liver Physiol. 2014; 307:G140G148. [PubMed: 24833710]

99. Hiebel C, Kromm T, Stark M, Behl C. Cannabinoid receptor 1 modulates the autophagic flux independent of mTOR- and BECLIN1-complex. J Neurochem. 2014; 131:484-497. [PubMed: 25066892]

100. Piyanova A, et al. Loss of CB1 receptors leads to decreased cathepsin D levels and accelerated lipofuscin accumulation in the hippocampus. Mech Ageing Dev. 2013; 134:391-399. [PubMed: 23954857]

101. Höhn A, Grune T. Lipofuscin: formation, effects and role of macroautophagy. Redox Biol. 2013; 1:140-144. [PubMed: 24024146]

102. Andrew SE, et al. The relationship between trinucleotide (CAG) repeat length and clinical features of Huntington's disease. Nature Gen. 1993; 4:398-403.

103. Byers RK, Gilles FH, Fung C. Huntington's disease in children Neuropathologic study of four cases. Neurology. 1973; 23:561-569. [PubMed: 4267989]

104. Blazquez C, et al. Loss of striatal type 1 cannabinoid receptors is a key pathogenic factor in Huntington's disease. Brain. 2011; 134:119-136. [PubMed: 20929960]

105. Naydenov AV, et al. Genetic rescue of CB1 receptors on medium spiny neurons prevents loss of excitatory striatal synapses but not motor impairment in HD mice. Neurobiol Dis. 2014; 71:140 150. [PubMed: 25134728]

106. Chiarlone A, et al. A restricted population of CB1 cannabinoid receptors with neuroprotective activity. Proc Natl Acad Sci USA. 2014; 111:8257-8262. [PubMed: 24843137]

107. Noonan J, et al. Endocannabinoids prevent $\beta$-amyloid-mediated lysosomal destabilization in cultured neurons. J Biol Chem. 2010; 285:38543-38554. [PubMed: 20923768]

108. Sarnataro D, et al. Plasma membrane and lysosomal localization of CB1 cannabinoid receptor are dependent on lipid rafts and regulated by anandamide in human breast cancer cells. FEBS Lett. 2005; 579:6343-6349. [PubMed: 16263116] 
109. Rozenfeld R. Type I cannabinoid receptor trafficking: all roads lead to lysosome. Traffic. 2011; 12:12-18. [PubMed: 21040297]

110. Brailoiu GC, et al. Agonist-selective effects of opioid receptor ligands on cytosolic calcium concentration in rat striatal neurons. Drug Alcohol Depend. 2012; 123:277-281. [PubMed: 22196236]

111. Bénard G, et al. Mitochondrial CB1 receptors regulate neuronal energy metabolism. Nature Neurosci. 2012; 15:558-564. This paper suggests that CB1 receptors are present on mitochondria and that mitochondrial CB1 signalling modulates neuronal functions. [PubMed: 22388959]

112. Morozov YM, et al. Antibodies to cannabinoid type 1 receptor co-react with stomatin-like protein 2 in mouse brain mitochondria. Eur J Neurosci. 2013; 38:2341-2348. [PubMed: 23617247]

113. Witte ME, Mahad DJ, Lassmann H, van Horssen J. Mitochondrial dysfunction contributes to neurodegeneration in multiple sclerosis. Trends Mol Med. 2014; 20:179-187. [PubMed: 24369898]

114. Cravatt BF, et al. Supersensitivity to anandamide and enhanced endogenous cannabinoid signaling in mice lacking fatty acid amide hydrolase. Proc Natl Acad Sci USA. 2001; 98:93719376. [PubMed: 11470906]

115. Taschler U, et al. Monoglyceride lipase deficiency in mice impairs lipolysis and attenuates dietinduced insulin resistance. J Biol Chem. 2011; 286:17467-17477. [PubMed: 21454566]

116. Morgese MG, Cassano T, Cuomo V, Giuffrida A. Anti-dyskinetic effects of cannabinoids in a rat model of Parkinson's disease: role of CB(1) and TRPV1 receptors. Exp Neurol. 2007; 208:110 119. [PubMed: 17900568]

117. Lastres-Becker I, et al. Compounds acting at the endocannabinoid and/or endovanilloid systems reduce hyperkinesia in a rat model of Huntington's disease. J Neurochem. 2003; 84:1097-1109. [PubMed: 12603833]

118. Huang SM, et al. Identification of a new class of molecules, the arachidonyl amino acids, and characterization of one member that inhibits pain. J Biol Chem. 2001; 276:42639-42644. [PubMed: 11518719]

119. Verhoeckx KC, et al. Presence, formation and putative biological activities of $N$-acyl serotonins, a novel class of fatty-acid derived mediators, in the intestinal tract. Biochim Biophys Acta. 2011; 1811:578-586. [PubMed: 21798367]

120. Hu SS, et al. The biosynthesis of $N$-arachidonoyl dopamine (NADA), a putative endocannabinoid and endovanilloid, via conjugation of arachidonic acid with dopamine. Prostaglandins Leukot Essent Fatty Acids. 2009; 81:291-301. [PubMed: 19570666]

121. Schmidt-Hieber C, Jonas P, Bischofberger J. Enhanced synaptic plasticity in newly generated granule cells of the adult hippocampus. Nature. 2004; 429:184-187. [PubMed: 15107864]

122. Chemin J, Cazade M, Lory P. Modulation of T-type calcium channels by bioactive lipids. Pflugers Arch. 2014; 466:689-700. [PubMed: 24531745]

123. Alhouayek M, Muccioli GG. COX-2-derived endocannabinoid metabolites as novel inflammatory mediators. Trends Pharmacol Sci. 2014; 35:284-292. [PubMed: 24684963]

124. Woodward DF, et al. The pharmacology and therapeutic relevance of endocannabinoid derived cyclo-oxygenase (COX)-2 products. Pharmacol Ther. 2008; 120:71-80. [PubMed: 18700152]

125. Valdeolivas $\mathrm{S}$, et al. The inhibition of 2-arachidonoyl-glycerol (2-AG) biosynthesis, rather than enhancing striatal damage, protects striatal neurons from malonate-induced death: a potential role of cyclooxygenase-2-dependent metabolism of 2-AG. Cell Death Dis. 2013; 4:e862. [PubMed: 24136226]

126. Nomura DK, et al. Endocannabinoid hydrolysis generates brain prostaglandins that promote neuroinflammation. Science. 2011; 334:809-813. This study identifies COX2 as a major metabolism pathway of the endocannabinoid 2-AG that mediates neuroinflammation and neuronal loss in a mouse model of Parkinson's disease, suggesting that COX2 inhibitors might represent promising therapeutic approaches for this neurodegenerative disease. [PubMed: 22021672]

127. Chen X, Zhang J, Chen C. Endocannabinoid 2-arachidonoylglycerol protects neurons against $\beta$ amyloid insults. Neuroscience. 2011; 178:159-168. [PubMed: 21256197] 
128. Chen R, et al. Monoacylglycerol lipase is a therapeutic target for Alzheimer's disease. Cell Rep. 2012; 2:1329-1339. [PubMed: 23122958]

129. Ho KW, Ward NJ, Calkins DJ. TRPV1: a stress response protein in the central nervous system. Am J Neurodegener Dis. 2012; 1:1-14. [PubMed: 22737633]

130. Li HB, et al. Antistress effect of TRPV1 channel on synaptic plasticity and spatial memory. Biol Psychiatry. 2008; 64:286-292. [PubMed: 18405883]

131. González-Aparicio R, Moratalla R. Oleoylethanolamide reduces L-DOPA-induced dyskinesia via TRPV1 receptor in a mouse model of Parkinson's disease. Neurobiol Dis. 2014; 62:416-425. [PubMed: 24140894]

132. Razavinasab M, et al. Pharmacological blockade of TRPV1 receptors modulates the effects of 6OHDA on motor and cognitive functions in a rat model of Parkinson's disease. Fundam Clin Pharmacol. 2013; 27:632-640. [PubMed: 23216087]

133. Sigel E, et al. The major central endocannabinoid directly acts at $\mathrm{GABA}_{\mathrm{A}}$ receptors. Proc Natl Acad Sci USA. 2011; 108:18150-18155. [PubMed: 22025726]

134. Du H, Chen X, Zhang J, Chen C. Inhibition of COX-2 expression by endocannabinoid 2arachidonoylglycerol is mediated via PPAR- $\gamma$. Br J Pharmacol. 2011; 163:1533-1549. [PubMed: 21501147]

135. Naydenov AV, et al. ABHD6 blockade exerts antiepileptic activity in PTZ-induced seizures and in spontaneous seizures in R6/2 mice. Neuron. 2014; 83:361-371. This study identified ABHD6 as a therapeutically valid anti-epileptic target that is not associated with drug-treatment tolerance and psychotropic effects. [PubMed: 25033180]

136. Pryce G, et al. Control of experimental spasticity by targeting the degradation of endocannabinoids using selective fatty acid amide hydrolase inhibitors. Mult Scler. 2013; 19:1896-1904. [PubMed: 23625705]

137. De Petrocellis L, et al. Effects of cannabinoids and cannabinoid-enriched Cannabis extracts on TRP channels and endocannabinoid metabolic enzymes. Br J Pharmacol. 2011; 163:1479-1494. [PubMed: 21175579]

138. Leweke FM, et al. Cannabidiol enhances anandamide signaling and alleviates psychotic symptoms of schizophrenia. Transl Psychiatry. 2012; 2:e94. [PubMed: 22832859]

139. Webb M, Luo L, Ma JY, Tham CS. Genetic deletion of fatty acid amide hydrolase results in improved long-term outcome in chronic autoimmune encephalitis. Neurosci Lett. 2008; 439:106110. [PubMed: 18501510]

140. Rossi S, et al. Cannabinoid CB1 receptors regulate neuronal TNF-a effects in experimental autoimmune encephalomyelitis. Brain Behav Immun. 2011; 25:1242-1248. [PubMed: 21473912]

141. Mazzola C, Micale V, Drago F. Amnesia induced by $\beta$-amyloid fragments is counteracted by cannabinoid CB1 receptor blockade. Eur J Pharmacol. 2003; 477:219-225. [PubMed: 14522360]

142. van der Stelt M, et al. A role for endocannabinoids in the generation of parkinsonism and levodopa-induced dyskinesia in MPTP-lesioned non-human primate models of Parkinson's disease. FASEB J. 2005; 19:1140-1142. [PubMed: 15894565]

143. Horne EA, et al. Downregulation of cannabinoid receptor 1 from neuropeptide $Y$ interneurons in the basal ganglia of patients with Huntington's disease and mouse models. Eur J Neurosci. 2013; 37:429-440. [PubMed: 23167744]

144. Dowie MJ, et al. Altered CB1 receptor and endocannabinoid levels precede motor symptom onset in a transgenic mouse model of Huntington's disease. Neuroscience. 2009; 163:456-465. [PubMed: 19524019]

145. Bilsland LG, et al. Increasing cannabinoid levels by pharmacological and genetic manipulation delay disease progression in SOD1 mice. FASEB J. 2006; 20:1003-1005. [PubMed: 16571781]

146. Steindel F, et al. Neuron-type specific cannabinoid-mediated $G$ protein signalling in mouse hippocampus. J Neurochem. 2013; 124:795-807. This study shows that CB1 receptor coupling efficacy in glutamatergic neurons is greater than in GABAergic neurons, providing evidence for an additional level of complexity in the differential signalling measured for this GPCR depending on the cell type. [PubMed: 23289830]

147. van der Stelt M, et al. Endocannabinoids and $\beta$-amyloid-induced neurotoxicity in vivo: effect of pharmacological elevation of endocannabinoid levels. Cell Mol Life Sci. 2006; 63:1410-1424. 
The first study showing different time-dependent changes in anandamide and 2-AG levels, and a dual beneficial and exacerbating action on disease signs by endocannabinoids, in a model of amyloid- $\beta$-induced toxicity. [PubMed: 16732431]

148. Mulder J, et al. Molecular reorganization of endocannabinoid signalling in Alzheimer's disease. Brain. 2011; 134:1041-1060. This study, along with REF. 147 identifies increased 2-AG levels as a possible maladaptive mechanism contributing to some signs in amyloid- $\beta$-induced toxicity. [PubMed: 21459826]

149. Bari M, et al. In vitro and in vivo models of Huntington's disease show alterations in the endocannabinoid system. FEBS J. 2013; 280:3376-3388. [PubMed: 23659592]

150. Johnston TH, et al. Fatty acid amide hydrolase (FAAH) inhibition reduces L-3,4dihydroxyphenylalanine-induced hyperactivity in the 1-methyl-4-phenyl-1,2,3,6tetrahydropyridine-lesioned non-human primate model of Parkinson's disease. J Pharmacol Exp Ther. 2011; 336:423-430. [PubMed: 20966038]

151. Bouchard J, et al. Cannabinoid receptor 2 signaling in peripheral immune cells modulates disease onset and severity in mouse models of Huntington's disease. J Neurosci. 2012; 32:18259-18268. [PubMed: 23238740]

152. Fernandez-Ruiz J, et al. Prospects for cannabinoid therapies in basal ganglia disorders. Br J Pharmacol. 2011; 163:1365-1378. [PubMed: 21545415]

153. Kim K, Moore DH, Makriyannis A, Abood ME. AM1241, a cannabinoid CB2 receptor selective compound, delays disease progression in a mouse model of amyotrophic lateral sclerosis. Eur $\mathbf{J}$ Pharmacol. 2006; 542:100-105. [PubMed: 16781706]

154. González S, et al. Effects of rimonabant, a selective receptor antagonist, in a rat model of cannabinoid CB 1 Parkinson's disease. Brain Res. 2006; 1073-1074:209-219. 


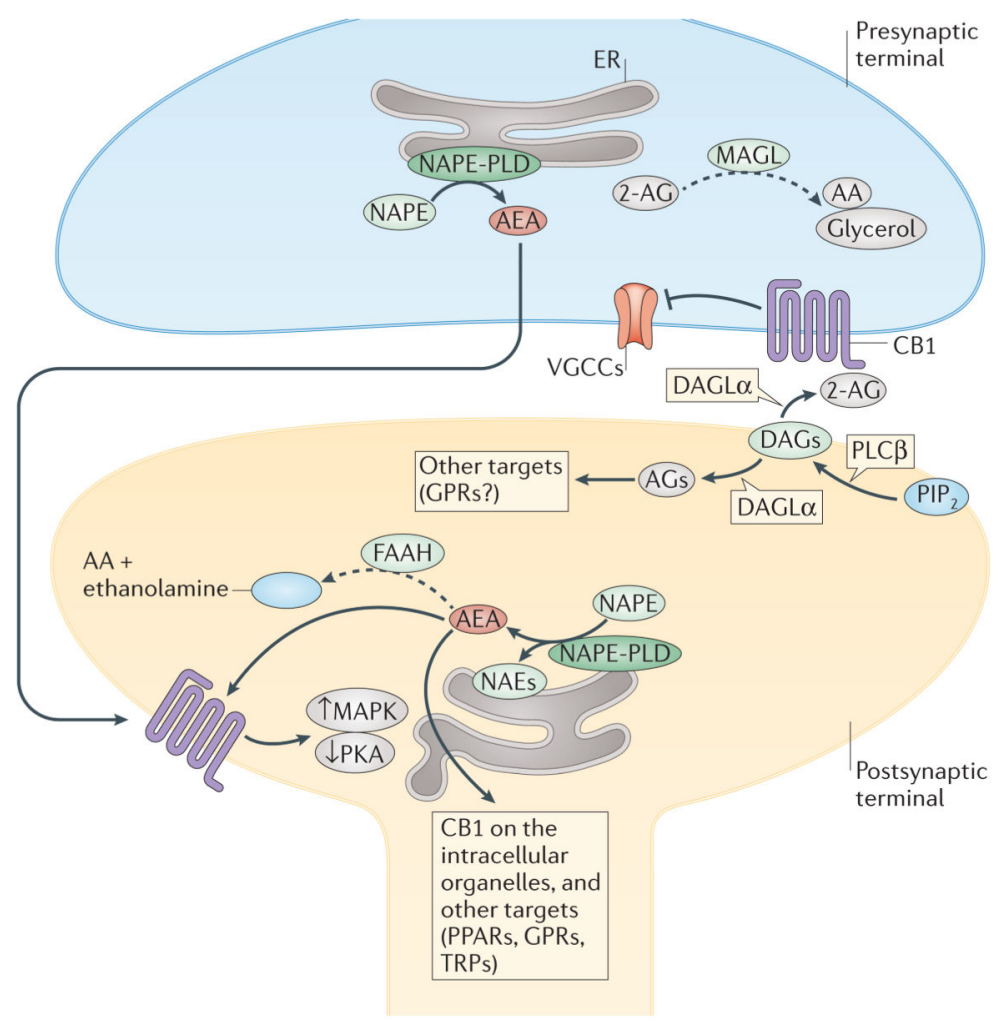

Figure 1. Main biosynthetic and inactivating enzymes in endocannabinoid signalling The subcellular distribution in neurons of enzymes regulating the levels of endocannabinoids (eCBs) is shown, including the proposed role of these lipid mediators in retrograde (mainly for 2-arachidonoyl-glycerol (2-AG)), anterograde and intracellular (for anandamide (AEA)) signalling. The biosynthesis of AEA occurs through the action, among others, of $N$-acylphosphatidylethanolamine (NAPE)-specific phospholipase D (NAPE-PLD), which is located in intracellular membranes both pre- and postsynaptically. AEA is degraded by fatty acid amide hydrolase 1 (FAAH), which is located postsynaptically. This distribution of the enzymes responsible for synthesis and degradation of AEA enables this and other $N$ acylethanolamines (NAEs) to function as anterograde signals acting at postsynaptic targets, or as intracellular mediators. 2-AG is biosynthesized by diacylglycerol lipase-a (DAGLa), which is located postsynaptically, and degraded by monoacylglycerol lipase (MAGL), which instead is presynaptic, thus accounting for the retrograde signalling action suggested for this endocannabinoid (see FIG. 2b). The complexity arising from the fact that many of these enzymes also regulate the levels of eCB-related mediators, with non-cannabinoid receptors as targets, is also depicted. For further complexity in eCB signalling see FIG. 4 and Supplementary Information S1 (table). Solid arrows denote transformation into active metabolites or activation; dashed arrows denote transformation into metabolites inactive at cannabinoid receptors; blunt arrow denotes inhibition. AA, arachidonic acid; AGs, 2acylglycerols; DAGs, diacylglycerols; ER, endoplasmic reticulum; GPRs, orphan G-proteincoupled receptors; MAPK, mitogen-activated protein kinases; $\mathrm{PIP}_{2}$, phosphoinositide bisphosphate; PKA, protein kinase A; PLC $\beta$, phospholipase C $\beta$; PPARs, peroxisome 
proliferator-activated receptors; TRPs, transient receptor potential channels; VGCCs, voltage-gated calcium channels. 

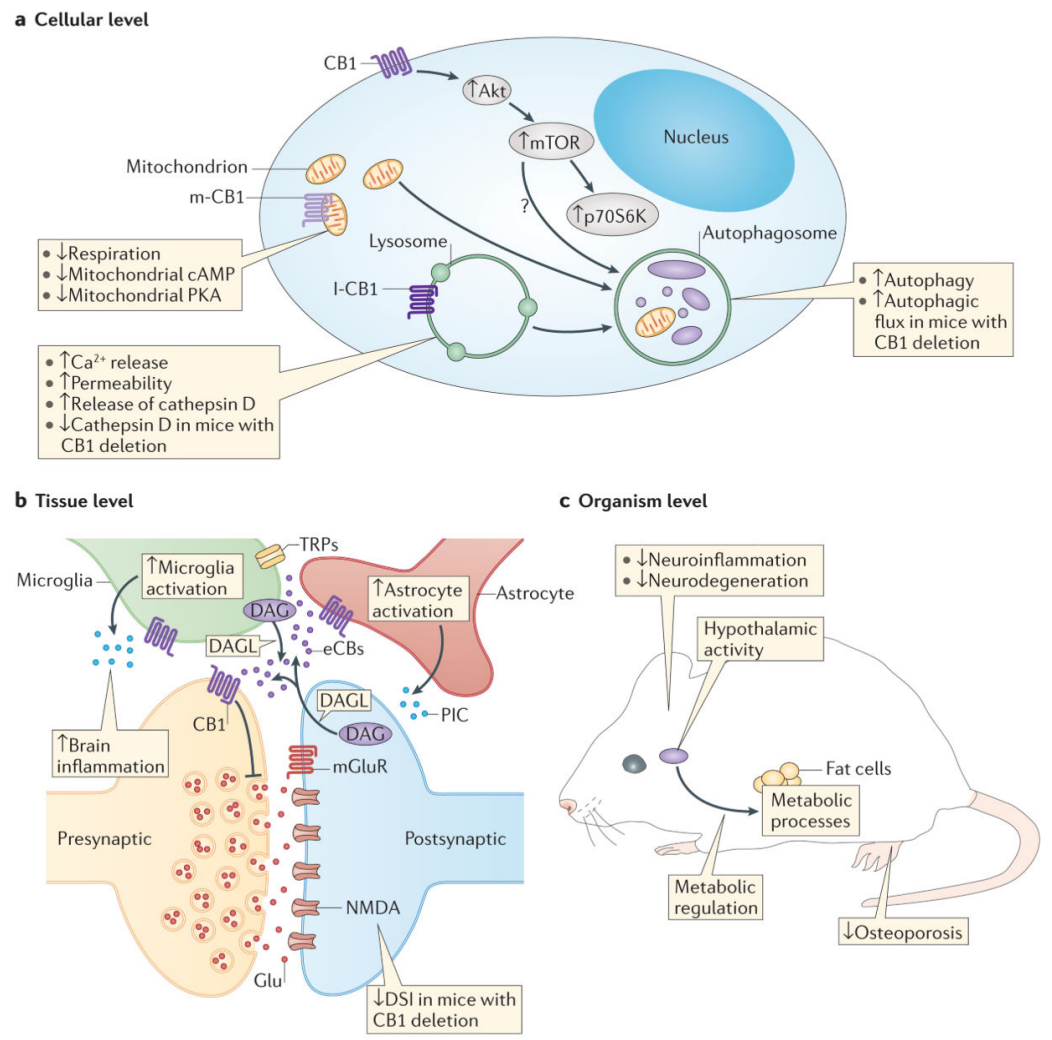

Figure 2. Age-related changes at different system levels and their regulation by endocannabinoid signalling

Ageing is accompanied by changes in cellular processes, impairments in the integration of cellular activities, and deficits in physiological functions. a $\mid$ At the cellular level, important hallmarks of ageing in the CNS are impairments in mitochondrial functions, disruption of proteostasis and autophagy, and alterations in signalling pathways involved in nutrient sensing, such as the mammalian target of rapamycin (mTOR) pathway. Endocannabinoids (eCBs) act as intracellular signalling molecules that modulate mitochondrial activity through cannabinoid type 1 (CB1) receptors located either in the plasma membrane or on lysosomes (1-CB1) and possibly mitochondria (m-CB1). In particular, activation of $\mathrm{m}-\mathrm{CB} 1$ seems to reduce mitochondrial respiration, and to decrease mitochondrial cyclic AMP levels and protein kinase A (PKA) activity ${ }^{11}$. CB1 receptors located on lysosomes enhance the intracellular release of $\mathrm{Ca}^{2+}$, increase the permeability of lysosomes and the release of cathepsin D. CB1 receptors on the cell surface also stimulate mTOR signalling, through an Akt-dependent mechanism, resulting in an enhanced activity of phosphoprotein 70 ribosomal protein S6 kinase (p70S6K). The mechanism by which cannabinoids stimulate autophagy is not entirely clear (indicated by a question mark), and is probably independent of mTOR. b | At the tissue level, disruption of intercellular communication is another hallmark of ageing. Endocannabinoids are best known as signalling molecules for shortrange cell-cell communication. At synapses they provide a retrograde feedback system, in which activation of presynaptic CB1 receptors reduces neurotransmitter release probability. Endocannabinoids also modulate the activity of astrocytes and microglia. These cells may also be a source for brain endocannabinoids (eCBs). Increased numbers of activated 
microglia and astrocytes are typically found in the ageing brain and result in an increased production of pro-inflammatory cytokines (PICs). This process leads to a change towards a more pro-inflammatory milieu in the brain. $\mathbf{c} \mid$ At the organism level, eCBs modulate the activity of several systems that are important in ageing, such as metabolic processes or hypothalamic activity. Cannabinoids are generally protective against age-related pathologies, including neuroinflammation and neurodegeneration. They also protect against some age-related pathologies outside the CNS, such as osteoporosis ${ }^{58}$. Akt, serine/threonine Akt; DAG, diacylglycerol; DAGLs, diacylglycerol lipases; DSI, depolarization-induced suppression of inhibitory neurotransmission; Glu, Glutamate; IC, intracellular; mGluR, metabotropic glutamate receptor; NMDA, $N$-methyl-D-aspartate; PKA, protein kinase A; TRP, transient receptor potential channel. 

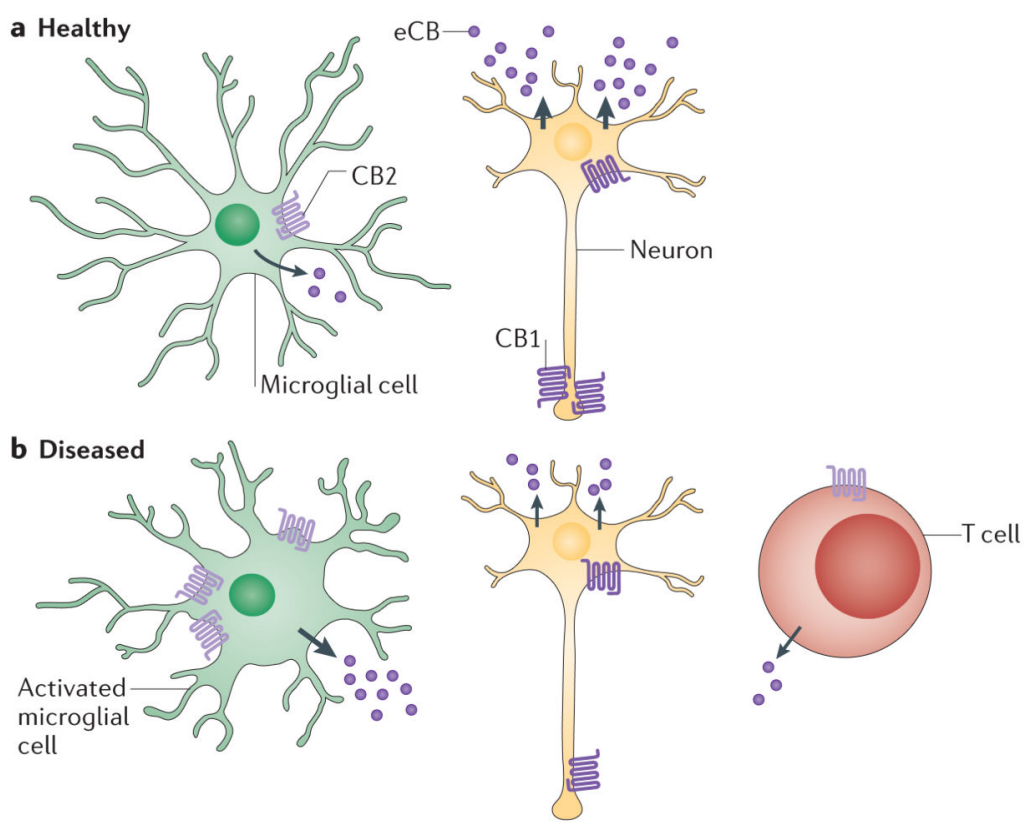

Figure 3. Effect of neuroinflammation on endocannabinoid signalling a In healthy brain tissue, neurons express cannabinoid receptor 1 (CB1) receptors in the dendritic tree and also higher levels at axon terminals. Resting microglia express low levels of $\mathrm{CB} 2$ receptors ${ }^{73}$. Endocannabinoid $(\mathrm{eCB})$ production by neurons is high (indicated by the thick arrows), whereas eCB production in microglia is low (indicated by the thinner arrow). b | In diseased brain in which the immune system has been activated (for example, in multiple sclerosis), the cell-specific expression profile of cannabinoid receptors changes, resulting in lower levels of $\mathrm{CB} 1$ receptors in both the dendritic tree and axon terminal of neurons and higher expression of CB2 receptors in activated microglia. In addition, $\mathrm{T}$ cells expressing low levels of $\mathrm{CB} 2$ receptors invade the diseased brain area ${ }^{75,77}$. eCB production by neurons decreases (indicated by the thinner arrows), while eCB production in microglia increases (thick arrow). This overall change in the cell-specific expression profile of cannabinoid receptors and eCB levels in brain as a function of disease and possibly of the ageing process suggests that the responses of humans to cannabinoid-based therapeutics is likely to differ depending on the age of the patient and disease phase. 

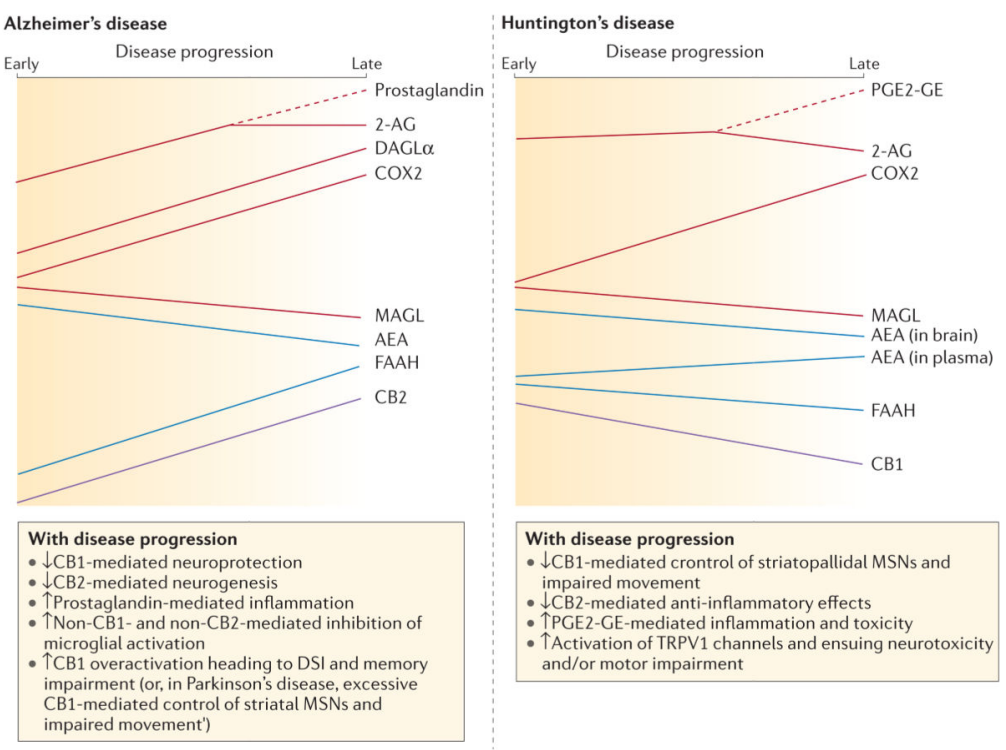

Figure 4. The endocannabinoidome in neurodegenerative diseases

The complexity of the alterations of components of the endocannabinoid (eCB) system and of some elements of the 'endocannabinoidome', in terms of redundancy of metabolic pathways, involvement of non-cannabinoid type 1 (CB1), non-CB2 receptors and tissue- or time-dependent changes is summarized. Time-dependent changes of the brain levels of some of the eCB synthesizing and inactivating enzymes and eCBs, and of the expression of eCB molecular targets, in animal models of neurodegenerative diseases (and, when available, in post-mortem brains of patients with these disorders) are depicted with their potential consequences. Red lines indicate changes in 2-arachidonoyl-glycerol (2-AG) and its metabolic enzymes or products over time during the progression of either Huntington's or Alzheimer's disease. Time-dependent changes in anandamide (AEA) and fatty acid amide hydrolase 1 (FAAH) over the course of these diseases are shown in blue. Purple lines denote changes in CB1 and CB2 during Alzheimer's and Huntington's disease. Note that CB1 and CB2 receptor levels are unchanged in Alzheimer's disease and Huntington's disease, respectively (not shown). Dashed branches show when a mediator begins to be partially metabolized into another one. In this case, the levels of the mediator being transformed start being reduced and those of its product start being increased. Note how the levels of AEA and 2-AG may change in different or opposite ways in the two conditions. They can also produce opposite effects $^{147,148}$, depending on the production of cyclooxygenase 2 (COX2) metabolites (in the case of 2-AG) ${ }^{125-128}$ or because of activation of non-cannabinoid receptors (for example, transient receptor potential cation channel subfamily $\mathrm{V}$ member 1 (TRPV1) channels in the case of AEA) ${ }^{116,117}$. Also within the same disorder, a given eCB may first increase and then decrease (as with $2-\mathrm{AG}$ in Alzheimer's disease) ${ }^{147}$, or change in opposite ways in different brain areas or blood (as with AEA in Huntington's disease) ${ }^{149}$. Finally, some of the features of Alzheimer's disease, such as the formation of 2-AG-derived prostaglandins, or the participation of $\mathrm{CB} 1$ receptors in determining some of the symptoms ${ }^{148}$, also occur in models of Parkinson's disease. DSI, depolarization-induced 
suppression of inhibitory neurotransmission; MSNs, medium-spiny neurons; PGE2-GE, prostaglandin E2 glycerol ester. 


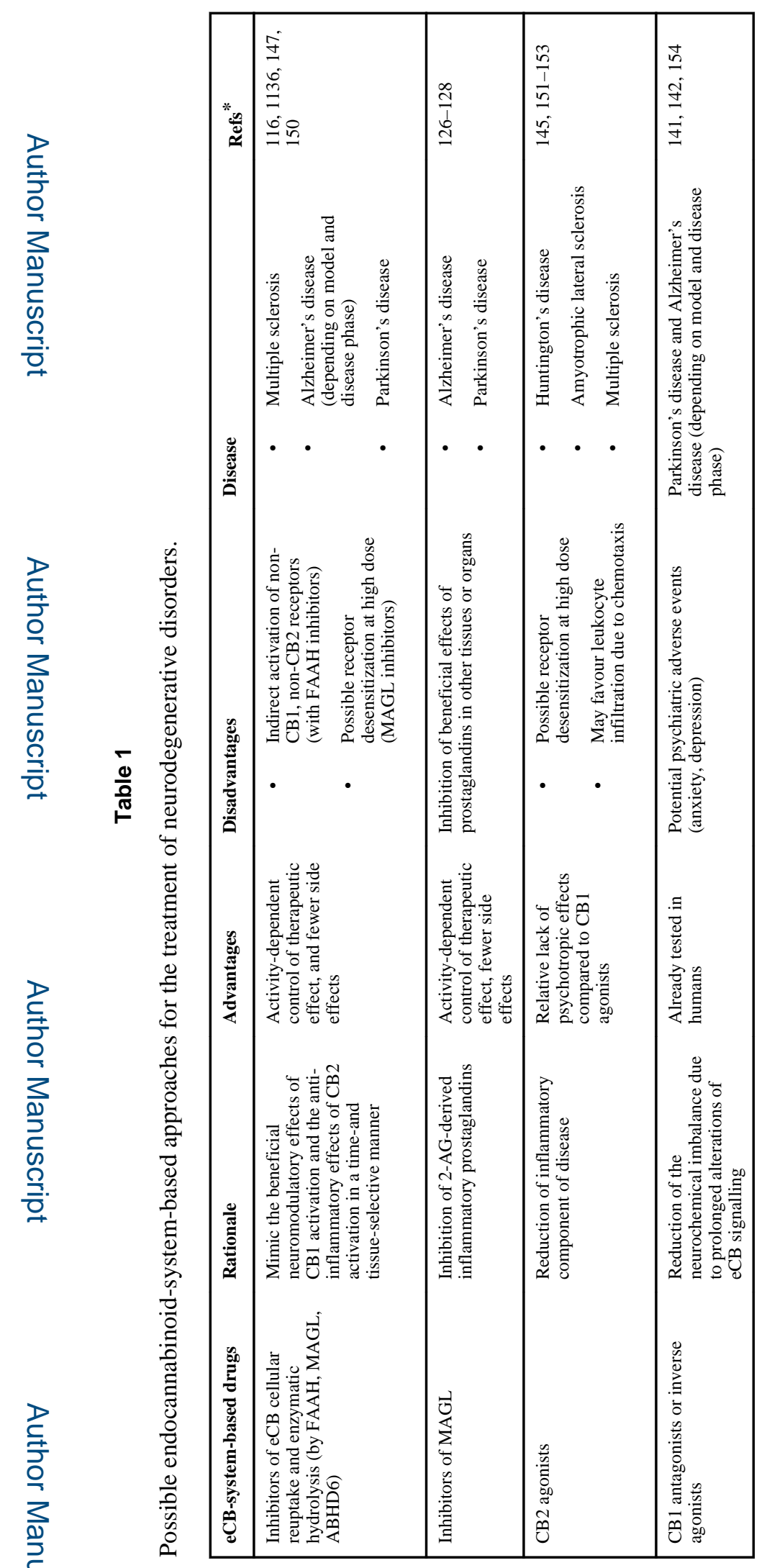

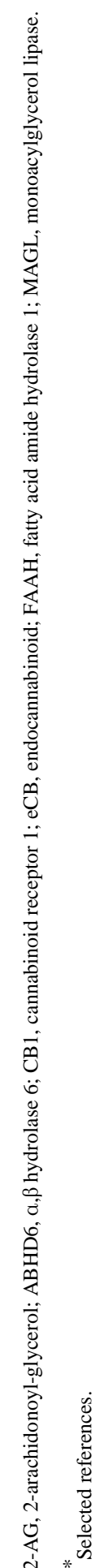

Nat Rev Neurosci. Author manuscript; available in PMC 2015 June 18. 